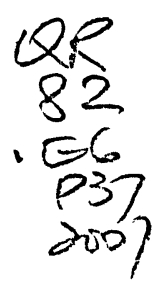

\title{
THE ROLE OF PI3K SIGNALING IN
}

\section{ENTEROPATHOGENIC ESCHERICHIA COLIINDUCED APOPTOSIS IN EPITHELIAL CELLS}

\author{
By \\ Heather Park \\ Bachelor of Science, Ryerson University, Toronto, 2004 \\ A thesis \\ presented to Ryerson University \\ in partial fulfillment of the \\ requirements for the degree of \\ Master of Applied Science \\ in the program of \\ Environmental Applied Science and Management
}

Toronto, Ontario, Canada, 2007

(C) Heather Park 2007 


\section{INFORMATION TO USERS}

The quality of this reproduction is dependent upon the quality of the copy submitted. Broken or indistinct print, colored or poor quality illustrations and photographs, print bleed-through, substandard margins, and improper alignment can adversely affect reproduction.

In the unlikely event that the author did not send a complete manuscript and there are missing pages, these will be noted. Also, if unauthorized copyright material had to be removed, a note will indicate the deletion.

\section{$\mathrm{UMI}$}

UMI Microform EC53575

Copyright 2009 by ProQuest LLC

All rights reserved. This microform edition is protected against unauthorized copying under Title 17, United States Code.

ProQuest LLC

789 East Eisenhower Parkway

P.O. Box 1346

Ann Arbor, MI 48106-1346 


\section{Author's Declaration}

I hereby declare that I am the sole author of this thesis.

I authorize Ryerson University to lend this thesis to other institutions or individuals for the purpose of scholarly research.

I further authorize Ryerson University to reproduce this thesis by photocopying or by other means, in total, or in part, at the request of other institutions or individuals for the purpose of scholarly research.

5

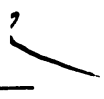




\title{
The Role of PI3K Signaling in Enteropathogenic Escherichia coli Induced Apoptosis
}

\author{
(C) Heather Park 2007 \\ Master of Applied Science \\ Environmental Applied Science and Management \\ Ryerson University, Toronto, 2007
}

\begin{abstract}
Enteropathogenic Escherichia coli (EPEC) is a diarrheagic pathogen that has been the cause of severe and persistent infant diarrhea worldwide. EPEC invades the gastrointestinal tract where it hijacks host cell signaling and evades immune responses long enough to cause disease. This study was done to establish the role of PI3K signaling in EPEC induced apoptosis in epithelial cells. This report demonstrates that EPEC infected cells activate the anti-apoptotic signaling protein, Akt via phosphorylation along with another anti-apoptotic signaling protein, Bcl-2. At the same time during EPEC infection the proapoptotic protein Bax is inhibited. The activation of Akt was also observed with the addition of lipopolysaccharide (LPS) in the presence of serum. This thesis suggests that there are likely separate sensing mechanisms for EPEC, LPS and serum that are independent but synergistic and that Akt is the integration site of these signaling cascades.
\end{abstract}




\section{Acknowledgements}

There are a variety of people that I would like to thank for making this thesis possible.

Firstly, I would like to thank my advisor, Dr. Debora Foster for her knowledge, perceptiveness and constant motivation during my research. I would also like to thank my co-advisor Dr. John Marshall for his constant enthusiasm and expertise in protein science. Together they have encouraged my growth as an independent researcher and heightened my appreciation for scholarly research.

I would like to thank the Lingwood laboratory at the Hospital for Sick Children for their help, use of laboratory space and supplies during my research. Furthermore, I would like to thank the many people at Ryerson University for the funny hallway chat that made me laugh when I most needed it.

I am indebted to the School of Graduate Studies at Ryerson University for scholarship funding, which made my thesis financially possible.

Finally, special thanks to Dave, my family and friends for their constant support and understanding during the madness. Thank You Everyone! $<3$ 
Author's Declaration

Abstract

Acknowledgements

List of Tables

List of Figures

\subsection{INTRODUCTION}

1.1 GENERAL INTRODUCTION

1.2 ATtACHMENT AND ADHESION

1.3 Host Cell Signaling

1.4 ANTI-APOPTOTIC SIGNALING

1.5 Other Signaling Proteins

1.6 LIPOPOLYSACCHARIDE

1.7 PuRPOSE OF INVESTIGATION AND HYPOTHESIS

2.1 Chemicals Used

2.2 BACTERIAL GROWTH

2.3 Cell Culture

2.4 TREATMENTS PROTOCOLS:

2.5 Preparation of Cell lysate

2.6 Calculation of Protein Concentration

2.7 ProteIn ANALYSIS

2.8 Preparation of Frozen Competent Eschericia COLI

2.9 TRANSFORMATION OF PLASMIDS INTO COMPETENT CELLS

2.10 TRANSFECTION OF DNA INTO HUMAN CELL LINES

3.1 RESULTS PREAMBLE

3.1 AKT ACTIVATION BY EPEC INFECTION

3.2 AKT ACTIVATION BY LIPOPOLYSACCHARIDE

3.2.1 LIPOPOLYSACCHARIDE TIME COURSE

3.2.2 LIPOPOLYSACCHARIDE DOSE RESPONSE

3.3 AKT ACTIVATION BY EPEC INFECTION WITH LPS 
4.1 EFFECT OF EPEC INFECTION ON AKT PHOSPHORYLATION

4.2 EFFECT OF LIPOPOLYSACCHARIDE AND SERUM ON AKT ACTIVATION

4.3 EFFECT OF EPEC INFECTION AND LIPOPOLYSACCHARIDE ON AKT ACTIVATION

4.4 OTHER SIGNALING PROTEINS

51

4.4.1 CASPASE-9

51

4.4.2 BAX

52

4.4.3 BCL-2

53

4.6 SUMMARY OF RESULTS AND SIGNIFICANCE

54

5.0 REFERENCES

59 


\section{List of Tables}

Table 1: Cell Treatments for P-Akt identification 25

Table 2: Antibody Concentrations 30

Table 3: Characteristics of Plasmid Constructs 31

Table 4: Serum Starved Cells Infected With EPEC and Incubated With LPS or EGF. 36

Table 5: Serum Starved Cells Infected with EPEC and/or Incubated with LPS, Serum or Wortmannin. 37

Table 6: Cells Incubated in 1\%FBS Prior to Infection and Incubation with LPS.

Table 7: Cells Incubated in 1\% FBS Prior to Incubation with EPEC, LPS, Serum or Wortmannin.

Table 8. Cells Incubated in 10\% FBS Prortmannin. 40

Table 9: Cells Incubated in 10\% FBS 2 Days Prior to LPS, 41

Table 10 Overview of the Effect of EPEC, LPS and Serum on Akt Activation 42 


\section{List of Figures}

Figure 1 EPEC Pedestal Formation Inhibits Phagocytosis $\mathbf{5}$

Figure 2 Proposed Schematic of Early and Late EPEC Adhesion 7

Figure 3 Stress-Induced Caspase Cascade 10

Figure 4 Phosphoinositol-3 Kinase Signaling 12

Figure 5 Lipopolysaccharide Signaling 17

Figure 6: EPEC Infection Induces Phosphorylation of Akt in Serum. 34

Figure 7 LPS Time Course Using 100ng/mL LPS.

Figure 8 LPS Dose Response.

Figure 9: EPEC induces Akt Phosphorylation In Serum Starved cells 37

Figure 10: LPS Induces Weak Akt Phosphorylation in Serum Starved Cells. 38

Figure 11: Serum Affects the Induction of PI3K by EPEC Infection and LPS. 38

Figure 12: EPEC Infection Induces Phosphorylation of Akt in HEp-2 Cells in 1\% FBS. 40

Figure 13: EPEC Infection Activates PI3K in HEp-2 Cells Incubated in 10\% FBS 2 days Prior to Infection 42

Figure 14 Bax Levels Increase After $2 \mathrm{~h}$ of EPEC Infection.

\section{3}

Figure 15 Caspase-9 Activation Does Not Occur Within 6h of EPEC Infection. 44

Figure 16 Bcl-2 Levels Decrease as EPEC Infection Progresses 45

Figure 17 Akt As An Integration Site of Many Signaling Pathways 57 


\subsection{Introduction}

\subsection{General Introduction}

The success of infection by pathogenic bacteria greatly depends on the ability of the pathogen to attach to the host cell, secrete and translocate the appropriate proteins necessary for replication and ultimately survive. Enteropathogenic Escherichia coli (EPEC) is a diarrhegenic pathogen associated with severe and persistent infant diarrhea more commonly encountered in developing countries (Goosney et al., 1999; Nougayrede et al., 2003; Michgehl et al., 2006) and is responsible for approximately one million deaths per year worldwide (Wu et al., 2004).

Upon infection EPEC colonizes the small intestine but remains extracellular. It causes infection by intimately attaching to the cells causing attaching and effacing (AVE) lesions (Celli et al., 2001; Nougayrede et al., 2003). The AVE lesion is characteristic of EPEC infection and results from the degeneration of the brush border through cytoskeletal reorganization (Celli et al., 2001).

The locus of enterocyte effacement (LEE) pathogenicity island of EPEC encodes the proteins for operation and expression of the type three secretion system (TTSS) (Nougayrede et al., 2003; Torres et al., 2005; Quitard et al., 2006). The TTSS spans the membrane and delivers effector proteins necessary for the intimate attachment of the bacteria to the host cell and triggers host cell signaling (Quitard et al., 2006).

The versatility of $E$. coli occurs because of its variations in cell surface polysaccharides produced by the different strains (Whitfield \& Roberts, 1999). $E$. coli isolates have two serotype specific surface polysaccharides known as lipopolysaccharide (LPS) $\mathrm{O}$ antigen and capsular polysaccharide $\mathrm{K}$ antigen ((Whitfield, 2006). Variations in these polysaccharide structures give rise to the 
diversity of the E. coli and its $\sim 170 \mathrm{O}$ antigens and $\sim 80 \mathrm{~K}$ antigens (Whitfield, 2006). E. coli isolates that cause intestinal infections such as EPEC, ETEC and EHEC have their capsules related to LPS $O$ antigens (Whitfield, 2006). Many $E$. coli strains also produce an exopolysaccharide, colonic acid, which has no role in pathogenesis but may play a role in survival outside of the host cell since it is not produced in temperatures above $30^{\circ} \mathrm{C}$ (Whitfield \& Robe rts, 1999).

Epithelial cells are the first physical barrier that pathogens like EPEC encounter in the gut (de Grado et al., 2001). The colonization of the epithelial surface causes inflammation and a flurry of host cell signaling (Sansonetti, 2004). EPEC has been shown to induce host cell death (Crane et al., 1999; Abul-Milh et al., 2001). The induction of apoptosis may provide temporary advantages for EPEC such as nutrients and increased phosphatidylethanolamine (PE) levels, which results in increased binding (Abul-Milh et al., 2001; Khursigara et al., 2001). Conversely, the host cell immune response may also trigger apoptosis in an attempt to control bacterial infection (Abul-Milh et al., 2001)

There are three different processes in which cell death may occur, necrosis, apoptosis (Bonifacino, 2001; Bannerman \& Goldblum, 2003) and autophagy (Boya et al., 2005). Necrosis is thought to be a more passive process than apoptosis in that it is caused by trauma or cell damage, whereas apoptosis is considered to be a type of cell suicide (Bonifacino, 2001). Necrosis involves irreversible nucleic changes such as loss of cytoplasmic structure, mitochondrial dysfunction and cytolysis (Bonifacino, 2001; Bannerman \& Goldblum, 2003). Apoptosis is described as cell shrinkage, membrane blebbling, nuclear fragmentation and formation of apoptotic bodies (Bannerman \& Goldblum, 2003). Autophagic cell death is typified by the buildup of autophagic vacuoles (AV) (Boya et al., 2005) At the biochemical level all three cell death pathways activate Bcl-2 protection (Bonifacino, 2001; Boya et al., 2005). EPEC infection has been shown to elicit characteristics of necrosis and apoptosis of its host cell (Abul-Milh et al., 2001). 


\subsection{Attachment and Adhesion}

The process of microbial adhesion to host intestinal epithelial cell surfaces is essential to prevent them from being swept away and therefore requires specific interactions between adhesion molecules on the bacterial surface and receptors on the host cell (Huang et al., 1998; Nougayrede et al., 2003). Infection of host cells also requires that pathogens are able to take over cellular machinery to allow for replication (Pizarro-Cerda \& Cossart, 2004). Cellular lipids such as phosphoinositides modulate the function of the actin cytoskeleton and recruit effector proteins to the membrane (Pizarro-Cerda \& Cossart, 2004).

EPEC is a noninvasive bacterium that adheres in high numbers to tissue cultures in vitro (Nougayrede et al., 2003). The cell binding of most EPEC strains involves an initial non-intimate interaction with the formation of large microcolonies on the cell surface termed localized adherence (LA) ((Nougayrede et al., 2003; Torres et al., 2005). LA has been shown to be associated with the EPEC adherence factor (EAF) plasmid common to EPEC that demonstrate this phenotype (Nougayrede et al., 2003). The LA phenotype is mediated by type IV fimbriae, referred to as bundle forming pili (BFP) (Goosney et al., 1999; Torres et al., 2005). Tobe \& Sasakawa (2002) have demonstrated that BFP plays an important role in the cell type dependent adherence and in the later steps of EPEC adherence. Studies have shown that BFP is an essential virulence factor for EPEC pathogenesis (Giron et al., 1991; Torres et al., 2005).

After localized adherence, EPEC induces intimate attachment to the host

cell by inducing a lesion on the intestinal epithelial cells called the attaching and effacing ( $A / E$ ) lesion (Goosney et al., 1999; Nougayrede et al., 2003; Torres et al., 2005). AVE lesions are characterized by localized degeneration of the intestinal brush border surface, loss of microvilli and formation of pedestal like actin structures at the site of bacterial attachment (Savkovic et al, 1996; 
Nougayrede et al., 2003; Torres et al., 2005; Michgehl et al., 2006). In EPEC, the genes needed for the initiation of the AVE lesion are found on a $\sim 35 \mathrm{~kb}$ chromosomal pathogenicity island called the locus of enterocyte effacement (LEE) (Nougayrede et al., 2003; Michgehl et al., 2006).

The Type III secretion system (TTSS) which is a multi-protein complex that spans the membrane and directs delivery of effector proteins into the host cell is also encoded on the LEE (Nougayrede et al., 2003). The TTSS translocates many proteins into the host cell including intimin and its translocated intimin receptor (Tir) (Nougayrede et al., 2003). It is now known that for intimate attachment, cytoskeletal rearrangement and full virulence, intimin is an essential protein (Goosney et al., 1999; Nougayrede et al., 2003; Torres et al., 2005). The receptor for intimin was originally thought to be a host membrane protein but it is actually encoded by the LEE and is translocated by TTSS and is therefore named the translocated intimin receptor (Tir) (Nougayrede et al., 2003). Tir spans the host membrane and adopts a hairpin loop in the host cytoplasm where the $\mathrm{N}$ and the $\mathrm{C}$ terminus are exposed and extracellularly form the intimin domain (Nougayrede et al., 2003; Torres et al., 2005). The Tir protein also interacts with host cytoskeletal and signaling components using the $\mathrm{N}$ and $\mathrm{C}$-terminal domains in the host cytoplasm (Torres et al., 2005). Sinclair et al.' (2006) have shown that intimin also has close associations with nucleolin and $\beta 1$ integrins, which are present on the luminal surface of intestinal epithelia (Sinclair et al., 2006).

In the host cytoplasm, Tir is phosphorylated on two serine residues and a tyrosine residue, the latter of which is necessary for actin remodeling (Nougayrede et al., 2003). The binding of intimin to Tir causes a rearrangement of the cytoskeleton to form the pedestal on which EPEC resides (Goosney et al., 1999; Torres et al., 2005). The formation of the pedestals has been postulated to be a mechanism that enables EPEC to multiply in the extracellular space without being internalized by the host cell (Figure 1) (Pizarro-Cerda \& Cossart, 2004). The phosphoinositide (PI) pathway is affected during pathogenic infection by 
EPEC which blocks the activity of $\mathrm{PI}(3) \mathrm{K}$, causing the accumulation of Ptdlns $(4,5) \mathrm{P}_{2}$ at the phagocytic cups and pseudopod extensions and thus blockage of its internalization (Pizarro-Cerda \& Cossart, 2004; Hilbi, 2006). Recently it has been shown that EspF is an essential secreted TTSS effector molecule responsible for inhibiting PI3K-dependent uptake of EPEC by macrophages; however, the mechanism remains to be elucidated (Hilbi, 2006; Quitard et al., 2006). Figure 1 shows the association of Ptdlns $(4,5,) \mathrm{P}_{2}$ which controls the function and distribution of many actin binding proteins (PizarroCerda \& Cossart, 2004).

Figure 1 EPEC Pedestal Formation Inhibits Phagocytosis (Pizario-Cerda \& Cossart, 2004).

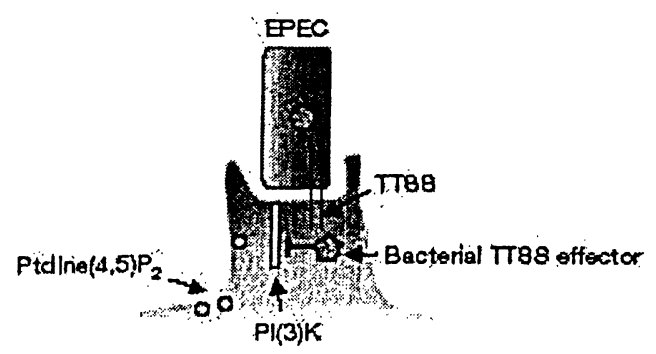

PI3Ks are required for the completion of phagocytosis and the disappearance of $\mathrm{PI}(4,5) \mathrm{P}_{2}$, which may occur through various pathways such as $\mathrm{PI} 3 \mathrm{~K}$ activity that increases $\mathrm{PI}(3,4,5) \mathrm{P}_{3}$ or $\mathrm{PLC} \delta$ activity that yields diacylglycerol (DAG) and inositol 1,4,5-triphosphate (IP3) (Hilbi, 2006). The accumulation of $\mathrm{PI}(3,4,5) \mathrm{P}_{3}$ has only been seen transiently during phagocytosis due to the rapid activity of phosphatases (Hilbi, 2006).

Kierbel et al (2005) demonstrated that PI3K is necessary for Pseudomonas aeruginosa entry into epithelial cells. They found that when using inhibitors for the downstream effector Akt, such as wortmannin and LY294002, internalization was abrogated (Kierbel et al., 2005). 
It has been shown that although intimin is an important protein for intimate attachment of EPEC to host cells it is not the only adhesin protein of EPEC (Nougayrede et al., 2003). Intimin mutants remain capable of colonizing the human, bovine and rabbit intestinal tract and adhere to tissue culture cells in vitro (Torres et al., 2005). The EspA protein encoded on LEE is also thought to be an adhesin (Nougayrede et al., 2003; Torres et al., 2005). EspA forms a filamentous extension of the TTSS and is proposed to form a conduit for the translocation of bacterial proteins into the host cell (Michgehl et al., 2006; Nougayrede et al., 2003). Two other proteins secreted through TTSS, EspB and EspD are essential for translocation of effector proteins into the host cell and have been thought to form a pore enabling the delivery of EPEC molecules (Torres et al., 2005; Michgehl et al., 2006).

EPEC produces BFP and it has been shown that antibodies against BFP inhibit LA (Nougayrede et al., 2003). Intimin has been shown to be an essential protein for $A V E$ and full virulence in humans, calves, mice and rabbits and therefore it has been found that antibodies against intimin prevent the colonization of host epithelial cells in animal models (Nougayrede et al., 2003). Intimin also induces mucosal hyperplasia and a massive TH1 immune response in mice, while mutant mice lacking intimin $\alpha$ failed to induce these responses (Nougayrede et al., 2003). Human studies have also found that in regions of high EPEC infection, high levels of antibodies against intimin $\alpha$ are found in infected individuals and the colostrums of nursing mothers (Nougayrede et al., 2003).

EPEC strains also have other surface structures that may be involved in adherence to host cells (Torres et al., 2005). A study by Giron et al (2002) showed that when EPEC is cultured with HeLa cells, flagellar expression is induced by an unknown eukaryotic protein. Structural studies of EPEC in vitro with scanning electron microscopy reveal appendages resembling flagella that span the microcolony and possibly mediate direct interactions with the epithelial 
cells (Giron et al., 2002). The flagellar filament and its monomer have also recently been shown to induce interleukin 8 in epithelial cells possibly leading to the observed inflammatory response during EPEC infection (Torres et al., 2005).

Figure 2 Proposed Schematic of Early and Late EPEC Adhesion (Torres et al., 2005)

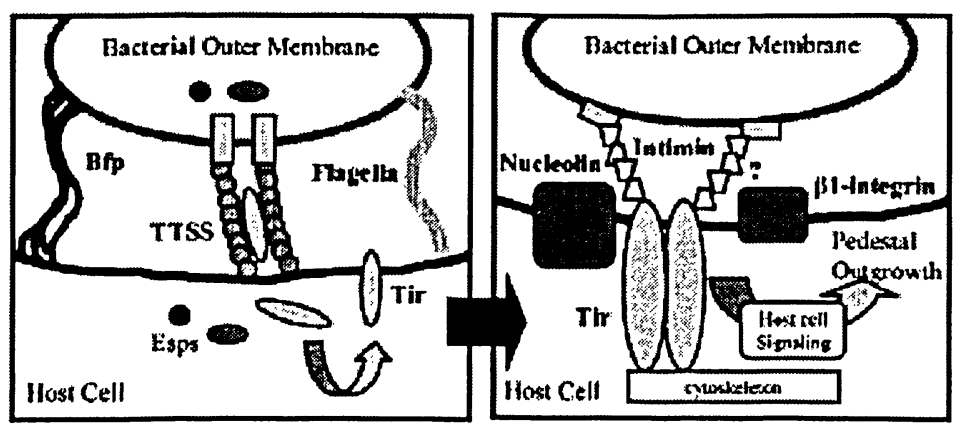

A number of host proteins accumulate in AVE lesion around Tir during EPEC infection and using its $\mathrm{N}$ - and $\mathrm{C}$ - terminals that are located in the host cytoplasm host signaling is manipulated and exploited (Torres et al., 2005). Interactions between Tir and intimin induce pedestal formation. The actin pedestal lengthens and shortens to allow movement of EPEC along the host cell surface (Goosney et al., 1999; Nougayrede et al., 2003). The pedestals are said to resemble microvilli in the distribution of actin and villin (Goosney et al., 1999).

During EPEC pathogenesis, intracellular levels of calcium have been shown to fluctuate and have therefore been implicated in the mechanism of pathogenesis (Goosney et al., 1999). EPEC interactions with PLC- $\gamma 1$ in HeLa epithelial cells show activation of numerous proteins like phospholipase C- $\gamma 1$ (PLC- $\gamma 1$ ) and the phosphorylation of PLC- $\gamma 1$ induces the inositol triphosphate $\left(\mathrm{IP}_{3}\right)$ and $\mathrm{Ca}^{2+}$ fluxes. $\mathrm{IP}_{3}$ is involved in the release of intracellular $\mathrm{Ca}^{2+}$ stores and increases $\mathrm{Ca}^{2+}$ concentration (Goosney et al., 1999). The buffering of intracellular calcium levels has been shown to prevent or delay the formation of AVE lesions (Goosney et al., 1999). The binding of EPEC to PE has also been 
shown to be inhibited by divalent cations, calcium and magnesium (Barnett Foster et al., 1999).

Recently Michgehl et al., (2006) have shown that under conditions of limited $\mathrm{Ca}^{2+}$, Tir integration into the host membrane can trigger the initiation of AVE lesion formation through an alternative Esp-independent mechanism. This was demonstrated when Tir was detected in the host cell membrane when using EspB and EspD mutants EPEC strains under low $\mathrm{Ca}^{2+}$ concentrations (Michgehl et al., 2006). Their data suggest that prior to the induction of signal transduction pathways involving host kinases, Tir is integrated into the host membrane from the cytosolic side (Michgehl et al., 2006). According to their model, Tir may be the initial protein needed for close adherence under certain environmental conditions such as low $\mathrm{Ca}^{2+}$ concentrations (Michgehl et al., 2006). This model still remains controversial and the mechanism in which these processes are controlled remains unclear (Michgehl et al., 2006).

\subsection{Host Cell Signaling}

Savkovic et al (1996) found that upon infection, EPEC induces the infiltration of inflammatory cells, such polymorphonuclear leukocytes (PMN). The adherence of EPEC and the activation of epithelial signaling pathways are necessary triggers for this to occur. It is therefore likely that the increase of inflammatory cells plays a role in the production of diarrhea, the classic symptom of EPEC infection (Savkovic et al., 1996).

During host cell infection, the TTSS secretes EspF, an effector protein that is translocated into host cells where it has been implicated as a disrupter of tight junctions (Nougayrede \& Donnenberg, 2004). This disruption leads to a decrease of transepithelial resistance, an increase in monolayer permeability and the redistribution of cytoplasmic occludin (a component of tight junctions) (Nougayrede \& Donnenberg, 2004). Nougayrede \& Donnenberg (2004) revealed 
through fluorescence microscopy that EspF appears as a focal accumulation and is targeted to a cellular organelle. They examined the location of EspF within infected HeLa cells using fluorescence confocal microscopy and saw that EspF colocalized with stained mitochondria and contained mitochondrial targeting motifs (MTS).

EspF has also been implicated as a possible mediator in host cell death in vitro and this is supported by findings that EPEC EspF mutants show severe attenuation in their ability to induce host cell death (Nougayrede \& Donnenberg, 2004). They also found that EspF has a role in the dissipation of mitochondrial transmembrane potential and the release of cytochrome $c$ in infected cells (Nougayrede \& Donnenberg, 2004).

The release of cytochrome $c$ from perturbed mitochondria into the cytoplasm where it induces the formation of the apoptosome and the activation of initiator, caspase-9, was observed by Nougayrede \& Donnenberg (2004). Caspase- 9 activates caspase- 3 which then cleaves caspase- 9 in a feedback amplification loop (Nougayrede \& Donnenberg, 2004). Caspases are known to play a critical role in apoptosis thus EspF is required for initiating the mitochondrial death pathway (Nougayrede \& Donnenberg, 2004).

BFP has also been shown to play a role in the induction of host cell death (Abul-Milh et al., 2001). Abul-Milh et al (2001) demonstrated that EPEC strains expressing BFP induced greater levels of cell death including apoptosis compared to those not expressing BFP. They also showed that a BFP complemented $E$. coli strain was able to induce significantly higher levels of host cell death than the uncomplemented parent strain.

Cell death induced by EPEC has been shown to have features of apoptosis such as nuclear internucleosomal DNA fragmentation (Barnett Foster et al., 1999; Abul-Milh et al., 2001; Nougayrede \& Donnenberg, 2004). EPEC- 
induced death also causes the release of ATP, which in turn induces a secretory response from neighboring cells (Nougayrede \& Donnenberg, 2004). Nougayrede and Donnenberg (2004) also indicate that EspF is sent to the mitochondria where it directly or indirectly modulates mitochondrial membrane permeability (MMP), cytochrome $c$ release and the mitochondrial death pathway. Figure 4 below depicts the induction of the caspase cascade resulting in apoptosis.

\section{Figure 3 Stress-Induced Caspase Cascade}

Adapted from (Bratton et al., 2000)

Mitochondrilal suress

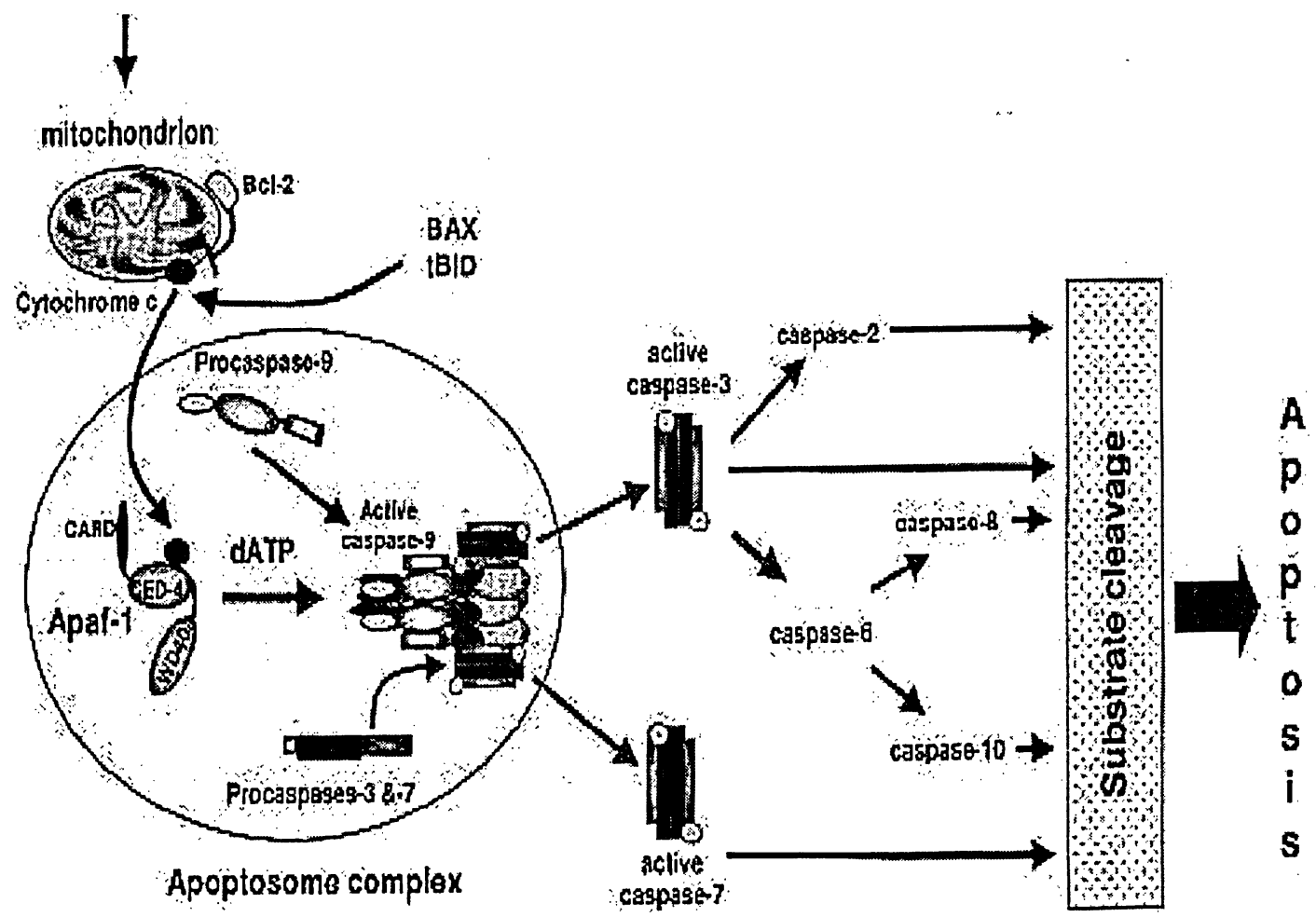

It has been postulated that apoptosis also involves the targeting of cell membrane phosphatidylethanolamine (Abul-Milh et al., 2001). Through the use of solid phase and liposome aggregation assays Barnett Foster et al (1999) was able to establish that EPEC recognizes phosphatidylethanolamine (PE) in a dose dependent manner and cells with lower PE demonstrate reduced bacterial 
binding. As apoptosis proceeds, there is an increase in outer leaflet PE levels, which correlate with increased binding of EPEC to the host cell (Abul-Milh et al., 2001). Since BFP expression correlates with $P E$ recognition and with the induction of apoptosis it has been hypothesized that BFP-PE binding plays a role in the induction of apoptosis (Abul-Milh et al., 2001; Wu et al., 2004). These findings are consistent with the tendency of PE to form the HII inverted micelle phase which promotes membrane changes that are associated with the formation of apoptotic bodies (Abul-Milh et al., 2001; Wu et al., 2004).

Wu et al., (2004) investigated the impact of bacterial adhesion on host phospholipid metabolism. Through the use of a series of pulse-chase experiments they found that EPEC infection is associated with transient changes in PE and phosphatidylcholine (PC) levels in the host cell changes which, correlated with the progression of EPEC induced apoptosis.

\subsection{Anti-Apoptotic Signaling}

Phosphoinositides are key players in many cell signaling events such as actin remodeling and membrane trafficking (Hilbi, 2006). Recently, cell survival has been linked in part to the PI3K/Akt kinase cascade (Datta et al., 1999). Figure 4 briefly describes the key players in PI signaling that lead to activation of Akt. 
Figure 4 Phosphoinositol-3 Kinase Signaling

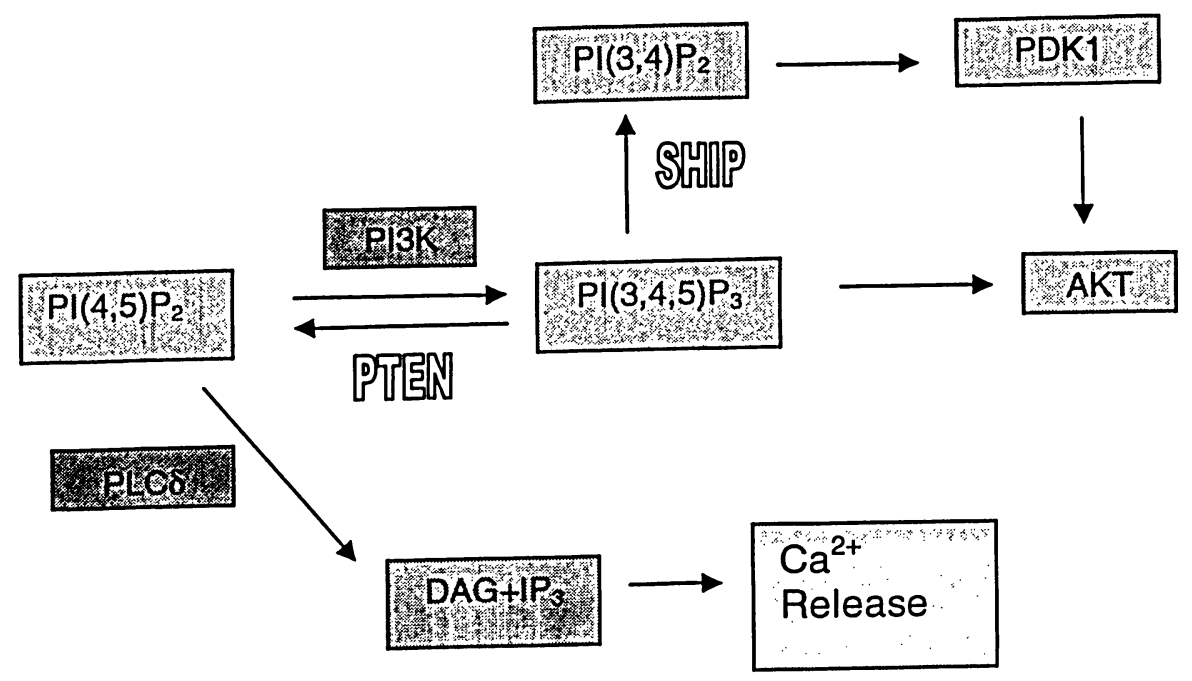

Some targets of the PI3K/Akt signaling cascade that have been identified as promoting survival include the inactivation of Bad and caspase 9, which are also a part of the cell death machinery (Datta et al., 1999). Activation of transmembrane receptors with kinase activity results in the recruitment of PI3K isoforms to the inner surface of the plasma membrane (Datta et al., 1999). Once localized, $\mathrm{PI} 3 \mathrm{~K}$ catalyzes the generation of phosphatidylinositol 3,4 bisphosphate $\left(\mathrm{PI}(3,4) \mathrm{P}_{2}\right)$ and $\mathrm{PI}(3,4,5) \mathrm{P}_{3}$ (Datta et al., 1999).

There is significant interest in identifying the targets of PI3K that block apoptosis. Akt and PKC are only two of the molecular targets that have been identified and these are relevant to the present study (Datta et al., 1999). PI3K phospholipids bind to Akt and thus cause its migration to the inner surface of the plasma membrane where it becomes activated via phosphorylation (Datta et al., 1999). There are also other survival stimuli that can activate Akt such as 
agonists of the PKA pathway. These can increase cytoplasmic calcium levels thus activating calcium/calmodulin dependent kinase kinase (CaMKK) that then phosphorylate Akt (Datta et al., 1999). An important part of the initiation to programmed cell death is the downregulation of Akt activity (Datta et al., 1999).

Akt is responsible for the delivery of anti-apoptotic survival signals through the phosphorylation and inactivation of Bad and caspase-9 and also the stimulation of NF-KB activity via activation of IKK $\alpha$ (Tang et al., 2001). Tang et al., (2001) suggested that either Akt cleavage during apoptosis is vital for cell survival or that its activation occurs during apoptosis as a "brake" on the process. Using the mitochondrial apoptotic stimuli staurosporine (STS), they found that overexpression of Akt delayed STS-induced apoptosis. Tang et al., (2001) aiso found that neither caspase inhibitors nor overexpression of $\mathrm{Bcl}-2$ or $\mathrm{Bcl}-\mathrm{x}_{\mathrm{L}}$ could prevent Akt activation by pro-apoptotic stimuli and thus it lay upstream of the mitochondrial signaling.

\subsection{Other Signaling Proteins}

The Bcl-2 family of proteins is involved in both apoptotic and anti-apoptotic signaling pathways (Datta et al., 1999). Cell survival is promoted by Bcl-2 and Bcl-X $X_{L}$ whereas Bax and Bad promote cell death (Datta et al., 1999). Korsmeyer and collegues showed that the activity of Bad was modulated by the addition of growth factors to GF-deprived cells (Datta et al., 1999). In the absence of survival factors, Bad becomes phosphorylated and associates with Bcl- $X_{L}$ thereby blocking cell survival (Datta et al., 1999).

It has been shown in multiple cell types that Akt blocks Bad-induced apoptosis via phosphorylation at Bad Ser-136 (Datta et al., 1999). Therefore when survival factors are present, an increase in Akt activity correlates with an increase in Bad phosphorylation (Datta et al., 1999). 
Bax is present in the cell cytosol and after a death signal will migrate to the mitochondrial membrane where it induces the release of cytochrome $c$ (Hui et al., 2004). The viability of most cells depends on the supply of cytokines or growth factors; therefore in the absence of these factors a cell may undergo apoptosis (Hui et al., 2004).

Tikhomirov \& Carpenter (2005) used epithelial growth factor (EGF) to induce apoptosis in MCF7 cells and found that Bax is gradually translocated to the mitochondrial outer membrane between $8-24 \mathrm{~h}$. At this time there was no indication of mitochondria membrane potential (MMP) loss, however after $48 \mathrm{~h}$ of EGF treatment, the cells show signs of MMP loss and Bax aggregate formation (Tikhomirov \& Carpenter, 2005). The interesting finding in these experiments was that EGF-induced apoptosis is independent of caspase activation. Although there is loss of MMP, cytochrome $c$ remains trapped within the mitochondria and therefore does not activate the caspase cascade (Tikhomirov \& Carpenter, 2005).

The activation and then cleavage of poly (ADP-ribose) polymerase (PARP) has also been shown to play an important role in apoptosis (Boulares et al., 1999). PARP catalyzes the poly ADP-ribosylation of different nuclear proteins using NAD as its substrate (Boulares et al., 1999). It is activated when it binds to DNA ends or strand breaks and thus is thought to deplete the cell of ATP and NAD. The cleavage of PARP inactivates it, essentially destroying its ability to attach and repair DNA strand breaks and stops its depletion of energy molecules in the cell (Boulares et al., 1999). Tang et al (2001) showed that PARP cleavage was delayed by the overexpression of Akt and thus is a good marker for apoptosis signaling in this research study. 


\subsection{Lipopolysaccharide}

Lipopolysaccharide (LPS) is a component of the Gram negative bacterial cell wall and has been shown to be a contributor to their sepsis (Bannerman \& Goldblum, 2003; Jacobsen et al., 2005; Pengal et al., 2006). When gramnegative bacteria are replicating and dying they release LPS from their surface, which consequently go into circulation (Bannerman \& Goldblum, 2003). LPS has been detected in the blood of septicemic patients and in some instances, levels of circulating LPS can predict the development of multi-organ failure (Bannerman \& Goldblum, 2003).

There are three main components to the LPS of $E$. coli (I) the lipid A hydrophobic portion that forms the outer leaflet of the outer membrane (II) the core oligosaccharide (core OS) which is a phosphorylated nonrepetitive heterooligosaccharide (III) a cell surface polysaccharide (O-PS) extension that forms the $O$ antigen which is detected in serotyping (Amor et al., 2000).

E. coli LPS is structurally diverse and as a result more than 170 known $O$ antigens exist (Amor et al., 2000). The core OS is separated into inner and outer regions (Amor et al., 2000). The inner core OS portion is phosphorylated and mainly consists of I-glycero-D-manno-heptose (heptose) and 3-deoxy-D-mannooct-2-ulosonic acid (Kdo) residues, which are conserved among enterobacteriaceae (Amor et al., 2000). This highly conserved region is thought to reflect the need for enterobacteria to have outer membrane stability (Amor et al., 2000). The outer core OS has a structural backbone consisting of a (hexose) 3 carbohydrate with two side chain residues however these may vary in nature, position and order (Amor et al., 2000).

Toll-like Receptor 4 (TLR4) is a receptor for LPS (Bannerman \& Goldblum, 2003; Kaufmann et al., 2005; Zughaier et al., 2004). When a complex of LPS and the LPS-binding protein (LBP) interacts with the CD14 receptor in 
monocytes, macrophages and dendritic cells, TLR4 signaling is initiated (Kaufmann et al., 2005). Cells lacking CD14 contain a soluble CD14 serum protein which substitutes for membrane bound CD14 and can activate the TLR4 signaling (Kaufmann et al., 2005). Phosphatidylinositol-3 kinase is activated after TLR4 signaling followed by downstream activation of Akt (Vivarelli et al., 2004)

Vivarelli et al (2004) showed that LPS induced PI3K activation is dependent on TAK1, which interacts with RIP. Their data suggest that RIP is essential for TAK1-dependent TLR4 and TLR9 activation of PI3K, although its exact mechanism has yet to be elucidated.

There is evidence that cross talk occurs between apoptotic signaling and LPS-induced NF-KB activation (Bannerman \& Goldblum, 2003). Proapoptotic FADD has been shown to downregulate LPS-induced NF-KB activation and thus changes in FADD levels can affect LPS-induced NF-KB activation, however under basal levels of FADD its inhibiting effects are unclear (Bannerman \& Goldblum, 2003). Caspase activation occurs through Caspase 8, which cleaves Caspase-3 though the exact mechanism of activation is unknown. FLICE-like inhibitor protein (FLIP) is an anti-apoptotic protein that contains homology with caspase-8 (FLICE). It has been shown to inhibit activation of upstream initiator caspases by competitive binding to FADD and thus protects the cell against LPSinduced apoptosis (Bannerman \& Goldblum, 2003). LPS has been shown to downregulate Bcl-2 (anti-apoptotic protein) and upregulate Bax levels. 


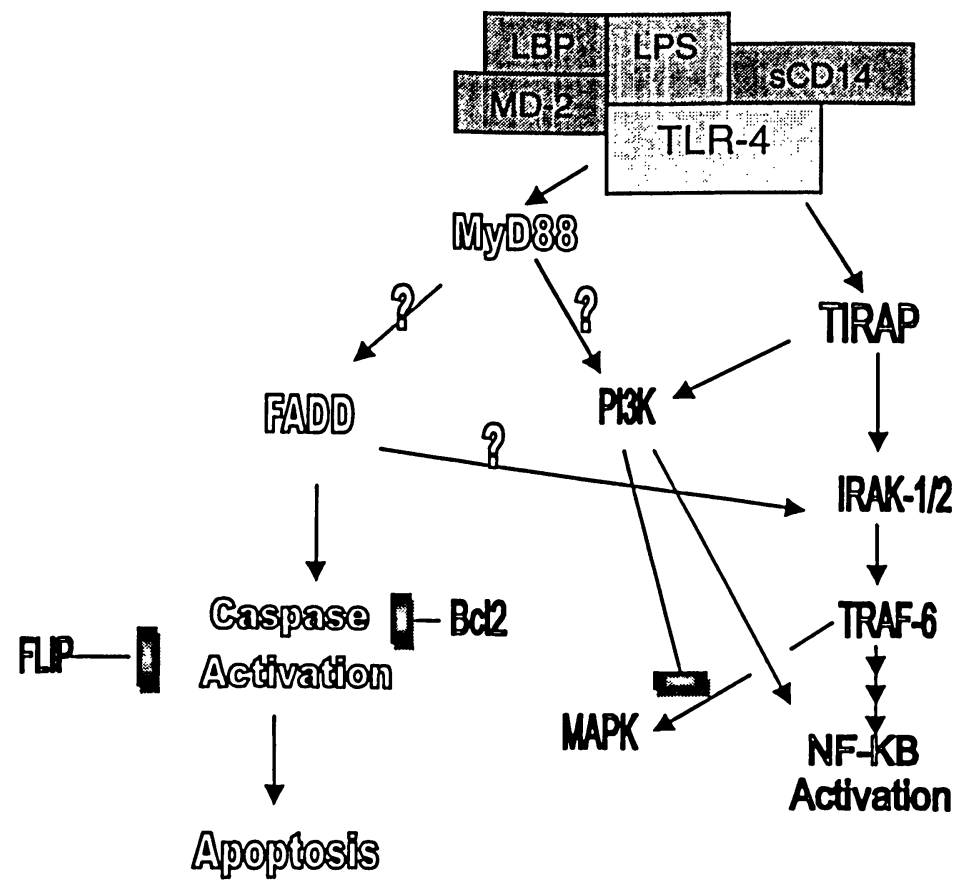

Figure 5 Lipopolysaccharide Signaling

After binding of LPS to TLR4 there are 2 major pathways MyD88-dependent and MyD88independent where nuclear translocation of NF-kB and apoptosis signaling events occur. There appears to be cross over between apoptosis and activation of NF- $\mathrm{kB}$. The proteins that link NF$\mathrm{KB}$ signaling to caspase activation remains to be elucidated. The exact mechanism of $\mathrm{PI} 3 \mathrm{~K}$ activation after LPS treatment is still unknown. Adapted from Monick et al., 2002; Bannerman et al., 2003

Zheng et al., (2006) used a mouse model to analyze the transcriptional responses to intramammary infusion of LPS. They found that a total of 489 genes were affected after 4h of LPS infusion, 391 of which were induced and 98 repressed (Zheng et al., 2006) The induced genes were mostly composed of immune response, apoptosis and cell proliferation. While the repressed genes included those responsible for carbohydrate and fatty acid metabolic enzymes and potassium transporters (Zheng et al., 2006)

The recognition of LPS by TLR4 initiates the activation of many intracellular signaling molecules along with the $1-\kappa B / N F-\kappa B$ cascade and the MAPK cascade (Bannerman \& Goldblum, 2003; Zheng et al., 2006). The I- 
$\kappa B / N F-\kappa B$ cascade causes the NF- $\kappa B$ transcription factor family (anti-apoptotic) while the MAPK cascade involves the activation of MAP kinase ( $\mathrm{p} 38$ and JNK), that then lead to the activation of the transcription factor AP1. Together the NF$\kappa B$ and AP-1 induce genes associated with cytokine biosynthesis, inflammatory response and chemotaxis (Fujioka et al., 2004; Zheng et al., 2006).

Growth factors and serum have been shown to induce AP-1 by activating ERK or MAPKs (Fujioka et al., 2004). The AP-1 transcription factors are mainly regulated through serum response elements (SREs) (Fujioka et al., 2004). The NF-KB p65 subunit has been shown to act as an accessory molecule for the serum response factor (Franzoso et al., 1996). The transcription factor serum response factor (SRF), is a known promoter of cell survival by the regulation of the expression of anti-apoptotic genes. Furthermore, SRF deficient cells have been found to have increased rates of apoptosis (Schratt et al., 2004). Even though NF-KB and AP-1 transcription factors are regulated through different mechanisms, they are activated simultaneously by the same stimuli and same signal transduction cascades (Fujioka et al., 2004). This shows that NF-kB and AP-1 transcription factors are involved in a synergistic relationship to promote cell survival.

LPS induces the stimulation of monocytes and macrophages which causes the intracellular signaling cascade that results in the production and release of cytokines and other inflammatory mediators such as IL-2, (TNF $\alpha$ ), IL1, IL-6 (these are tumor necrosis factors) (Kaufmann et al., 2005; Pengal et al., 2006). The deregulation of this signaling cascade often results in the fatal condition of septic shock and thus systemic inflammatory response syndrome (SIRS) (Kaufmann et al., 2005; Pengal et al., 2006).

LPS stimulation has previously been shown to activate PI3K, however its exact mechanism is yet to be completely elucidated (Bannerman \& Goldblum, 2003; Pengal et al., 2006). There are many contrary research reports to whether 
PI3K serves to up-regulate or down-regulate the pro-inflammatory response (Pengal et al., 2006).

It is well established that PI3K activity results in the production of $\mathrm{PI}(3,4,5) \mathrm{P}_{3}$, (PIP3), a crucial secondary signaling messenger (Pengal et al., 2006). When $\mathrm{PIP}_{3}$ accumulates, there is a recruitment of $\mathrm{PH}$-Domain-containing enzymes that function to activate AKT/PKB, a downstream effector of PI3K (Pengal et al., 2006). This activation has been shown to decrease lymphocyte apoptosis and thus improve survival in the cecal ligation and puncture model of sepsis (Pengal et al., 2006).

LPS has also been shown to be involved in the adherence and/or invasion of epithelial cells (Hoare et al., 2006). Early reports noted that LPS defective mutants of serovar Typhimurium were deficient in colonization of the mouse intestine. Hoare et al., (2006) investigated the role of LPS components in epithelial invasion of serovar Typhi by using mutants with gene deletions in both synthesis and polymerization of the $O$ antigen and assembly of the outer core. Their results indicated that not only the presence but also the proper distribution of $O$ antigens are required for serum resistance and the outer core terminal glucose residue is essential for entry of serovar Typhi into epithelial cells (Hoare et al., 2006).

Intestinal epithelial cells form the barrier that separates the host internal milieu form its external environment (Suzuki et al., 2003). The intestinal mucosa is exposed to commensal bacteria and their components on a regular basis and this elicits a 'normal' state of inflammation (Suzuki et al., 2003; Sansonetti, 2004). When the epithelial lining is compromised by pathogenic bacterial invasion an inflammatory response occurs (Suzuki et al., 2003; Sansonetti, 2004).

Recently it has been shown that inflammatory bowel disease (IBD) is induced by an abnormal immune response to normal bacterial flora within the gut 
(Fort et al., 2005). The murine mouse model has shown a clear dependence on enteric bacteria for the inflammatory response in the development of IBD, since when these are rendered germ-free the mice do not develop colitis (Fort et al., 2005). Therefore it may be possible to decrease IBD occurrence by blocking the ability of the immune system from responding to the bacteria (Fort et al., 2005).

The presence of specific bacterial Ags are identified by the immune system through pattern of recognition receptors (PRR) of which TLR4 is a part of (Sansonetti, 2004; Fort et al., 2005). It is known that LPS binds to TLR4 in a complex interaction between LPS, TLR4, CD14 and MD-2 (Bannerman \& Goldblum, 2003; Fort et al., 2005).

Signaling that occurs through TLR4 contributes to the inflammation response and recently it has been shown that molecules such as hyaluronic acid and heparin sulfate (present during inflammation) may also bind TLR4R (Fort et al., 2005). This indicates that the TLR4 complex may help to induce the inflammatory response and maintain it. Thus conditions of uncontrolled inflammatory response may be alleviated through the blocking of TLR4R (Fort et al., 2005).

It has been demonstrated that purified LPS in the absence of host derived mediators can evoke endothelial cell injury and apoptosis (Bannerman \& Goldblum, 2003). LPS treated rats have shown enhanced activation of caspase3 (Bannerman \& Goldblum, 2003)

\subsection{Purpose of Investigation and Hypothesis}

The balance between anti-apoptotic and pro-apoptotic signaling is crucial in determining whether a cell will undergo apoptosis (Hui et al., 2004). EPEC has been found to induce both apoptotic and anti-apoptotic signaling events in infected cells. Determining the levels of key host signaling proteins such as Akt, 
Bcl-2, Bax and Caspase-9 during EPEC infection should help to elucidate the signaling events that are occurring.

Since lipopolysaccharide (LPS) is a component of the bacterial gramnegative outer capsule and has been shown to activate PI3K signaling, it was necessary to assess the role of LPS in PI3K signaling as well as apoptotic signaling events during EPEC infection.

The objectives of this study were to establish the role of PI3K signaling in EPEC induced apoptosis in epithelial cells. More specifically the goals were to:

- Establish the time point in which Akt phosphorylation is occurring during EPEC infection

- Establish whether EPEC is inhibiting Akt phosphorylation at any point during infection

- To correlate the PI3K signaling with other signaling events during EPEC infection by monitoring $\mathrm{Bax}, \mathrm{Bcl}-2$ and Caspase-9 levels.

It is hypothesized that EPEC does activate PI3K signaling observed through phosphorylation of downstream effector Akt and that Akt activation delays apoptotic signaling as evidenced by Bax, Caspase- 9 and Bcl-2 levels.

\subsection{Materials and Methods}

\subsection{Chemicals Used}

Eagle's Minimal Essential Media (EMEM), Dulbecco's Modified Eagle Media (DMEM), phosphate buffered saline (PBS), Heat Inactivated Fetal Bovine Serum (FBS) were all purchased from MultiCell. Staurosporine (S6942), Lipopolysaccharide (L-2630), Protease Inhibitor Cocktail (P-8340) were purchased from Sigma, Toronto, ON. 
Total Akt (9272) and phosphorylated Akt 473 (4058) antibodies were purchased from Cell Signaling, Danvers, MA. Anti-Bax (554101) and anti-BCL-2 (554160) were purchased from BD Biosciences, anti-Caspase-9 p10 (118) (DB081) purchased from Delta Biolabs.

\section{Experimental Procedure}

\subsection{Bacterial Growth}

The wild-type enteropathogenic E. coli (EPEC) E2348/69 stock was stored at $-80^{\circ} \mathrm{C}$, while a culture was maintained at $4^{\circ} \mathrm{C}$ on Lu ria-Bertani (LB) agar plates. Prior to infection, one colony of EPEC was inoculated into $10 \mathrm{~mL}$ of LB broth and incubated for $16-18$ hours at $37^{\circ} \mathrm{C}, 200 \mathrm{rpm}$ (stationary phase). The non pathogenic EPEC strain, HB101, was treated in the same manner.

\subsection{Cell Culture}

The human laryngeal epithelial cell line, HEp-2, was obtained from the American Type Culture Collection (ATCC). The human intestinal epithelial cell line, Henle, was obtained from Dr. Devinney (University of Calgary). Both cell lines were grown in $250 \mathrm{~mL}$ flasks in a monolayer at $37^{\circ} \mathrm{C}, 5 \% \mathrm{CO}_{2}$. The HEp-2 cells were grown in Eagle's Minimal Essential Media (EMEM) and the Henle cells in Dulbecco's Modified Eagle Medium (DMEM) both obtained from (MultiCell) and supplemented with $10 \%$ heat inactivated fetal bovine serum (FBS).

\subsection{Treatments Protocols:}

\section{Epithelial Growth Factor}

Cell samples were grown to $85 \%$ confluency then serum starved for 18 hours prior to epithelial growth factor (EGF) treatment. For positive controls 
$100 \mathrm{ng} / \mathrm{mL}$ EGF was added to the serum starved cells for 10 mins. For infection protocols, bacteria were added with multiplicity of infection (MOI) of 100:1 for the indicated times and $100 \mathrm{ng} / \mathrm{mL}$ EGF was added for the final $10 \mathrm{mins}$ of incubation.

\section{Lipopolysaccharide}

Initial experiments indicated that cell confluency affected protein phosphorylation patterns, a finding also reported by Levea et al., (2004). Therefore cells samples used in LPS experiments were grown to $60-65 \%$ confluency in media (MEM/DMEM and FBS). This confluency was the lowest possible that would still provide sufficient sample protein concentrations.

\section{Initial LPS Conditions:}

$100 \mathrm{ng} / \mathrm{mL}$ LPS was added to the cells for various times $(5 \mathrm{~min}, 15 \mathrm{~min}$, $30 \mathrm{~min}, 1 \mathrm{~h}, 2 \mathrm{~h}, 4,6,24 \mathrm{~h}$ ) and the strongest band chosen as the optimal time to be used in the dose response experiments.

The presence of serum played a significant role in the resultant LPS signal. Negative control experiments were done to check at which point the basal P-Akt levels dissipated thus reducing the chances of false positives. The HEp-2 cells were incubated with $1 \%, 10 \%$ and $0 \%$ serum for various times and it was determined that after $24 \mathrm{~h}$ the basal P-Akt levels dissipated.

\section{LPS serum conditions:}

Cells were grown in $10 \% \mathrm{FBS}$ for $24-48 \mathrm{~h}, 37^{\circ} \mathrm{C}, 5 \% \mathrm{CO}_{2}$ prior to LPS treatment. Western blot analyses were used to determine optimal time and dosage of LPS treatments. 
Combined Bacterial and LPS treatment:

For sample treatments combining both bacterial infection and LPS, cells were infected with bacteria for the specified infections times, followed by addition of $10 \mathrm{ng} / \mathrm{mL}$ LPS for $1 \mathrm{~h}$ incubation, $37{ }^{\circ} \mathrm{C}, 5 \% \mathrm{CO}_{2}$.

After findings demonstrated that the LPS effect was greater in the presence of serum, it was added to the EPEC infection media instead of fresh EMEM.

\section{Bacterial Infection}

Both EPEC 2348/69 and HB101 were treated in the same manner for all infections. An overnight bacterial culture in LB when at stationary phase (16 to $18 \mathrm{hrs}$ after inoculation) was used to infect cell lines. $2.5 \mathrm{~mL}$ of bacteria cell suspension was inoculated into $17.5 \mathrm{~mL}$ of Dulbecco's Modified Eagle Medium (DMEM) with 25mM HEPES and incubated at $37 \%, 5 \% \mathrm{CO}_{2}$ for 2.5 to 3 hours. This incubation increased the growth rate so that the bacteria were in exponential phase.

After incubation $15 \mathrm{~mL}$ of bacteria suspension were taken and centrifuged at $3000 \mathrm{rpm}$ for 10 minutes at RT, and resuspended in fresh DMEM $+25 \mathrm{mM}$ HEPES. The remaining $5 \mathrm{~mL}$ suspension was used to determine its optical density (O.D.) reading using a Spectronic $20 \mathrm{TM}$ at wavelength of $600 \mathrm{~nm}$. The bacterial concentration was then calculated using equations previously obtained through standard growth curve experiments (Troyan, 2003). Equation 1 relates the turbidity of the bacterial suspension to the number of bacteria present in the EPEC suspension while Equation 2 refers to HB101 strain in the same manner.

Equation 1: $y=9 \times 10^{-10} x+0.0759$

Equation 2: $y=8 \times 10^{-10} x+0.0304$ 
Where $x$ is the O.D. reading and $y$ is the number of bacteria in the suspension. Cell lines were infected with a MOI of 100:1.

Infection Times:

Table 1: Cell Treatments for P-Akt identification

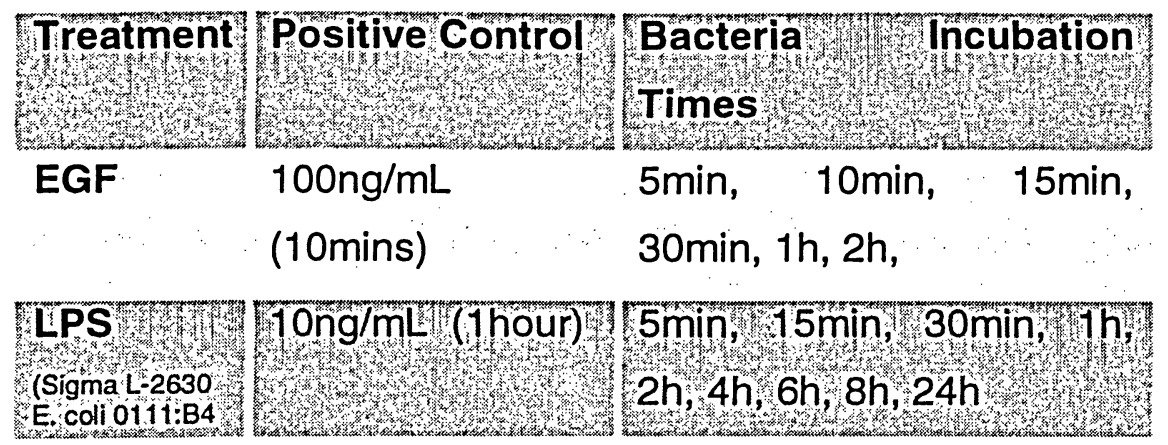

[Note: If infection time is longer than 2 hours the non-adherent bacteria are removed after 2 hours by washing with PBS and new fresh media is added ( $5 \mathrm{~mL}$ of EMEM)]

\subsection{Preparation of Cell Lysate}

\section{EGF Samples Preparation}

After treatment, incubation flasks were set on ice immediately and cells washed with ice cold PBS followed by addition of 400-500uL of ice cold PBS. The cells were scraped and transferred to an eppendorf tube on ice. The sample was centrifuged for $10 \mathrm{mins}, 4^{\circ} \mathrm{C}, 14000 \mathrm{rpm}$ and the pel let resuspended in $200 \mathrm{uL}$ of lysis buffer (Cell Signaling Lysis Buffer 10x + addition of the following just before using it; $1 \mathrm{mM}$ PMSF, $1 \mathrm{ug} / \mathrm{mL}$ pepstatin, $50 \mathrm{mM} \mathrm{NaF}, 1 \mathrm{ug} / \mathrm{mL}$ aprotinin) (Tang et al, 2001). At this point the pellet could be frozen at $-80^{\circ} \mathrm{C}$ and lysed at a later time. To lyse the pellet, it was placed on ice, a lysis buffer was added and it was vortexed for $5 \mathrm{sec}$. 
After resuspension of the pellet in lysis buffer, the sample was vortexed and set on ice for 20 minutes (and vortexed at the 10 min mark for 5 seconds). The cell suspension was then centrifuged at $4^{\circ} \mathrm{C}, 14000 \mathrm{rpm}$ for 10 minutes and supernatant collected in a sterile eppendorf and stored at $-80^{\circ} \mathrm{C}$.

\section{LPS Samples Preparation}

Initial experiments indicated that occasional degradation of the cell lysate occurred. Therefore, the method of cell lysis was modified to increase sample stability and the following procedure was adapted. After infection/treatment incubation cells were washed in ice cold PBS and then $300-400 \mathrm{uL}$ of boiling hot 2x sample buffer [ $4 \mathrm{x}$ Tris- $\mathrm{HCl}, \mathrm{pH} 6.8,0.4 \%(\mathrm{w} / \mathrm{v})$ sucrose, $0.8 \%(\mathrm{w} / \mathrm{v})$ SDS, Protease Inhibitor Cocktail (Sigma \#P8340) (10ul/mL), 50mM NaF, $1 \mathrm{mM} \mathrm{PMSF)}$ was added to the tissue culture flasks and the cells scraped into the corner and the flasks boiled for 5 minutes. The cell suspension was then collected into an eppendorf with a transfer pipet and boiled for another 30mins and then frozen at $20^{\circ} \mathrm{C}$ until needed.

\subsection{Calculation of Protein Concentration}

\section{BCA Assay}

The BCA ${ }^{\mathrm{TM}}$ Protein Assay Kit (Pierce Biotechnology, Rockford, IL.) was employed to determine the protein concentration of the EGF samples. The procedure was adapted from Pierce Biotechnology and the sample absorbances were read using a microplate reader at $560 \mathrm{~nm}$. A standard curve was generated using bovine serum albumin (BSA) protein standards and sample lysate protein concentration was determined using this standard curve. 
However after the adaptation of the $2 x$ sample buffer lysis protocol the concentration of SDS present in the samples was determined to be over the minimal interference levels and thus the dot blot method was adopted.

\section{Dot Blot Method}

Using the Dumbroff Dot Blot procedure (Ghosh et al., 1989) the protein concentration was measured. Briefly, a Whatmann \#1 filter paper was labeled with a pencil and $1 \mu \mathrm{l}$ of each standard and sample was dotted onto the paper and left to dry. The filter paper was then submerged in Coomasie brilliant blue stain $[(0.004 \%(\mathrm{w} / \mathrm{v})$ Coomasie brilliant blue, 5\% (v/v) Acetic acid, 5\% (v/v) $\left.\mathrm{MeOH}, \mathrm{H}_{2} \mathrm{O}\right]$ for 10 minutes with rocking. The dot blot was destained [10\%(v/v) $\mathrm{EtOH}, 10 \%(\mathrm{v} / \mathrm{v}) \mathrm{MeOH}, 10 \%(\mathrm{v} / \mathrm{v})$ Acetic Acid] for 1 hour followed by washing in $50 \%(\mathrm{v} / \mathrm{v}) \mathrm{MeOH}$ until most color had run out of filter paper. If filter paper was not fully destained the filter was dried then submerged in $100 \% \mathrm{MeOH}$ for 10 seconds then rinsed with $\mathrm{mqH}_{2} \mathrm{O}$ and the filter left to dry.

The protein dots on the filter were then measured for integrated density using the program ImageJ (http://rsb.info.nih.gov/ij/). The standards were measured then graphed and sample concentrations determined from the curve.

\subsection{Protein Analysis}

Protein Separation with SDS-PAGE Tris-Glycine

For the EGF treatments $12.5 \%$ resolving gels and $3.0 \%$ stacking gel were used to separate the sample proteins.

Prior to sample loading a 10x sample was added to the sample in a ratio of $1 \mu$ l of $10 x$ sample buffer to $9 \mu \mathrm{L}$ of sample protein. The mixture was then 
boiled for 5 minutes and $50 \mu \mathrm{g}$ protein loaded onto the gel. The gel was run at $100 \mathrm{~V}$ in running buffer [3\% (w/v) Tris, $14.4 \%(\mathrm{w} / \mathrm{v})$ glycine $\mathrm{pH} 8.3,1 \%(\mathrm{w} / \mathrm{v})$ SDS]

\section{Tricine Gel}

Before the LPS experiments began it was noted that tricine gels had a greater resolving power than tris-glycine gels. Therefore for future experiments involving LPS, the samples were resolved on tricine gels. $13 \%$ separating gels and $3 \%$ stacking gels were used.

Before loading samples into gel wells, approximately $4 \mathrm{mM}$ DTT and $0.01 \%(w / v)$ bromophenol blue color were added to the protein samples and boiled for 5 mins. A minimum of 40 ug of protein was loaded into each well. The inner chamber was filled with cathode buffer $[6 \%(w / v)$ Tris, $8.9 \%(w / v)$ tricine, $0.1 \%(w / v)$ SDS] and the outer chamber of the apparatus filled with an anode buffer [24.2\% (w/v) Tris, $\mathrm{pH}$ to 8.9$]$.

The gels were run at 125 constant voltage for $\sim 1.5$ hours.

\section{Protein Transfer}

A PVDF membrane (Milipore, Billerica, MA) was soaked in $100 \%$ methanol until fully wetted then washed with $\mathrm{mqH}_{2} \mathrm{O}$ and the transfer apparatus was set up. The gel and PVDF membrane were equilibrated in the transfer buffer in the apparatus 10 mins prior to running. Proteins were transferred for 90 minutes at $100 \mathrm{~V}$ in an ice bath.

After transfer the membrane was washed with $\mathrm{mqH}_{2} \mathrm{O}$ to wash off any residual gel then placed in $100 \% \mathrm{MeOH}$ for $10 \mathrm{~s}$ and then dried to ensure strong protein binding to the membrane. The blot was labeled with a pencil and then rewetted in $100 \%$ methanol and washed with $\mathrm{mqH}_{2} \mathrm{O}$ as above. The rewetted 
PVDF membrane was then submerged in Coomasie membrane stain (no acetic acid) for 10 mins to temporarily stain the proteins on the membrane to ensure equal protein loading was achieved. The membrane was then destained in $50 \%$ $\mathrm{MeOH}$ for 20 mins and left to dry and bands visualized. The remaining dye was removed using $100 \% \mathrm{MeOH}$. The membrane was then rinsed in $\mathrm{mqH}_{2} \mathrm{O}$ then rinsed in PBS and either left at $4^{\circ} \mathrm{C}$ until needed or used immediately.

\section{Western Blot Procedure}

To block residual binding sites on the membrane a block solution (5\% milk in $0.1 \%$ PBST, $1 \%$ antiserum) was added to the blot and incubated for 30 mins, RT, 75 rpm, followed by a 5 mins wash in wash buffer $(0.1 \%$ Tween 20 in PBS (PBST)). The blot was then overlay with the primary antibody at concentrations listed shown in Table 2 and incubated for 30 mins, RT, $75 \mathrm{rpm}$, followed by three 5 mins washes in wash buffer. The blot was then incubated with the secondary antibody for 30 mins, RT, $75 \mathrm{rpm}$, followed by two 5 mins and two 15 mins washes in wash buffer.

The excess buffer was removed and the blot incubated with ECL chemiluminescence solution for $1 \mathrm{~min}$. and the excess ECL removed and the blot placed in a plastic cover for imaging. The chemiluminescence was visualized using Kodak film. 
Table 2: Antibody Concentrations

\begin{tabular}{|c|c|c|c|}
\hline Antibody & Block & Primary. & Secondary \\
\hline Caspase-9 & $\begin{array}{l}5 \% \text { milk in } \\
0.1 \% \text { PBST } \\
+1 \% \text { Goat } \\
\text { antiserum }\end{array}$ & $\begin{array}{l}1: 1000 \\
\text { PBST }\end{array}$ & $\begin{array}{l}\text { GAR } 1: 10,000 \\
\text { in } 0.5 \% \text { Block }\end{array}$ \\
\hline 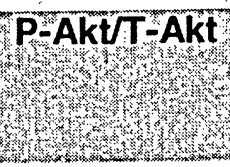 & $\begin{array}{l}5 \% \text { milk in } \\
0.1 \% \text { PBST } \\
+1 \% \text { Goat } \\
\text { serum }\end{array}$ & $\begin{array}{l}1: 2000 \text { in } 5 \% \\
\text { BSA in PBST } \\
\text { W }\end{array}$ & $\begin{array}{l}\text { GAR } 1: 15,000 \\
\text { in } 5 \% \text { BSA }\end{array}$ \\
\hline B-Actin & $\begin{array}{l}5 \% \text { milk in } \\
0.1 \% \text { PBST } \\
+1 \% \text { Goat } \\
\text { antiserum }\end{array}$ & $\begin{array}{l}\text { 1:2000 } \\
\text { PBST }\end{array}$ & $\begin{array}{l}\text { GAM } 1: 20,000 \\
\text { in PBST }\end{array}$ \\
\hline $\mathrm{Bax} / \mathrm{k}$ & 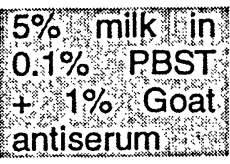 & 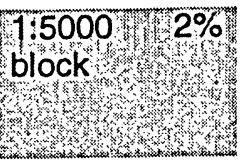 & 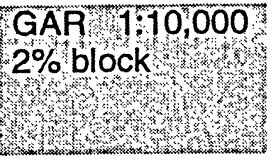 \\
\hline $\mathrm{BCl}_{2}$ & $\begin{array}{l}5 \% \text { milk in } \\
0.1 \% \text { PBST } \\
+1 \% \text { Donkey } \\
\text { antiserum }\end{array}$ & $\begin{array}{l}\text { 1:2000 } \\
\text { Block }\end{array}$ & $\begin{array}{l}\text { DAG } 1: 20,000 \\
\text { in } 2 \% \text { Block }\end{array}$ \\
\hline
\end{tabular}

\subsection{Preparation of Frozen Competent Escherichia coli}

Competent E. coli cells were made using E. coli strain $\mathrm{DH} 5 \alpha$ treated with rubidium chloride method. Briefly the $\mathrm{DH} 5 \alpha$ cells were grown in an overnight culture $(16-18 \mathrm{hrs})$ of $\mathrm{LB}$ at $37^{\circ} \mathrm{C}, 200 \mathrm{rpm}$. The culture was then streaked onto a $\mathrm{Y}$ media plate $[0.005 \%(\mathrm{w} / \mathrm{v})$ yeast extract, $0.02 \%(\mathrm{w} / \mathrm{v})$ tryptone, $0.005 \%(\mathrm{w} / \mathrm{v}) \mathrm{MgSO}_{4}{ }^{\star} 7 \mathrm{H}_{2} \mathrm{O}, \mathrm{pH} 7.6$ ] and left $16-18 \mathrm{hrs}$ at $37^{\circ} \mathrm{C}$. A colony was then reinoculated into $5 \mathrm{~mL} Y$ media and grown at $37^{\circ} \mathrm{C}, 200 \mathrm{rpm}$ till O.D. $\sim 0.3$. One $\mathrm{mL}$ from the cell suspension was reinnoculated into $100 \mathrm{~mL}$ prewarmed $Y$ media and grown until slightly cloudy (O.D. 0.35).

The cell suspension was then centrifuged at $4^{\circ} \mathrm{C}$ for $5 \mathrm{mins}, 3500 \mathrm{rpm}$. All subsequent steps were performed on ice. The pellet resuspended in 2/5 (i.e. if you started with $100 \mathrm{~mL}$ then you would use $40 \mathrm{~mL}$ ) Tfbl [Tfbl: $10 \mathrm{mM} \mathrm{CaCl}$, $30 \mathrm{mM}$ Potassium Acetate $100 \mathrm{mM} \mathrm{RbCl} 250 \mathrm{mM} \mathrm{MnCl}_{2}{ }^{*} 4 \mathrm{H}_{2} \mathrm{O}, 15 \%(\mathrm{v} / \mathrm{v})$ glycerol, $\mathrm{pH}$ 5.8] and left on ice for 5 mins then centrifuged for 5 mins, $4^{\circ} \mathrm{C}, 3500 \mathrm{rpm}$. The pellet was resuspended in 1/25 Tfbll solution [Tfbll: $10 \mathrm{mM}$ MOPS, $75 \mathrm{mM}$ 
$\mathrm{CaCl}_{2}{ }^{*} 2 \mathrm{H}_{2} \mathrm{O}, 10 \mathrm{mM} \mathrm{RbCl}, 15 \%(\mathrm{v} / \mathrm{v})$ glycerol, $\left.\mathrm{pH} 6.8\right]$ and left on ice for 15 mins. The cell suspension was then aliquoted and frozen at $-80^{\circ} \mathrm{C}$.

\subsection{Transformation of plasmids into competent cells}

The competent cells were thawed at room temperature then put on ice. Approximately $100 \mu \mathrm{L}$ cells per transformation were used [Constructs concentration was approximately $1 \mu \mathrm{g} / \mathrm{mL}$ therefore need to add $1 \mu \mathrm{L}$ DNA).

Table 3: Characteristics of Plasmid Constructs

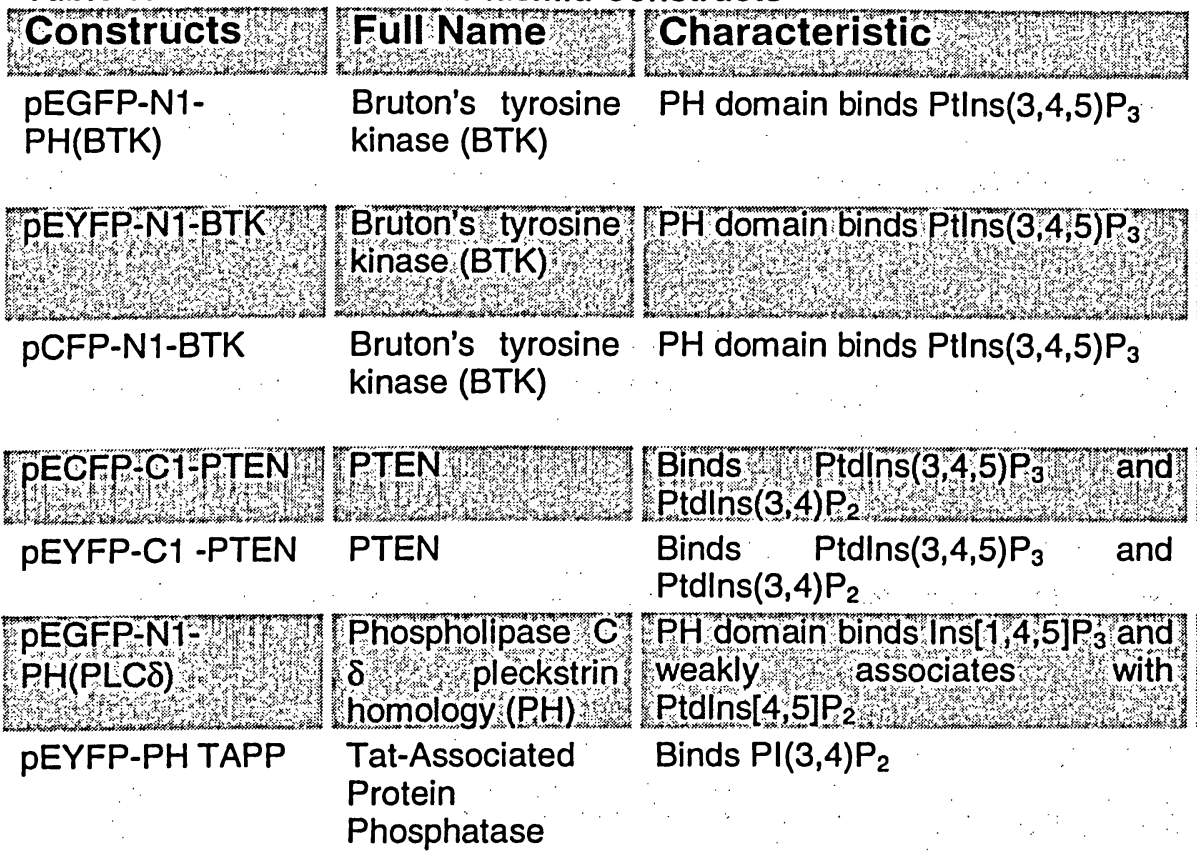

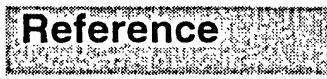

(Hirano et al., 2004 ; Varnai et al., 1999)

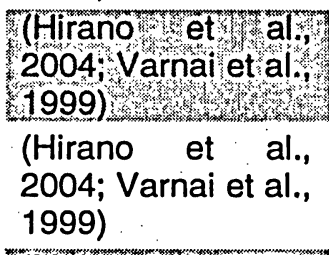

(Máer et al. 1999)

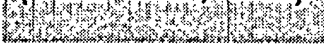

(Maier et al., 1999)

(Varnai \& \& Balla, 1998)

(Marshall et al., 2002)

The DNA was added to the competent cells and incubated on ice for 30 mins, followed by a heat shock at $42^{\circ} \mathrm{C}$ for $90 \mathrm{sec}$, proceeded by incubation on ice for another 2 mins. $1 \mathrm{~mL}$ of LB was added to the cells and incubated for $1 \mathrm{~h}$ at $37^{\circ} \mathrm{C}$. The cells were then plated out on 3 types of LB plates containing $50-100 \mathrm{ug} / \mathrm{mL}$ kanamycin, 50ug/mL ampicilin, and no antibiotic. The constructs contain a kanamycin resistance so only colonies that grew on the Kanamycin plates contained the transformed plasmid and were thus isolated. 
The DNA concentration was determined using UV/VIS spectrophotometer and the DNA stored at $-20^{\circ} \mathrm{C}$ until needed.

\subsection{Transfection of DNA into Human Cell Lines}

The constructs that were used were pEGFP-Akt-PH (Varnai et al., 2005) and pEGFP and pECFP-PTEN. Fugene-6 (Roche, Laval, Que.) was used to transfect the human cell lines with the isolated DNA. The cells were grown on cover slips in 6 well plates to confluency of $50-60 \%$ (log phase). Approximately lug of DNA was used per transfection. Controls were also made containing no DNA, just DNA and Fugene-6 treated to compare the transfections.

Briefly, Fugene $6^{T M}$ reagent was diluted in serum free media and gently mixed and incubated 5 mins, RT. Mixture was then added drop wise to an eppendorf containing lug DNA and incubated 15 mins, RT. The DNAFugene 6 mixture was then added drop wise to the cell wells and incubated $24-48 \mathrm{hrs}, 5 \%$ $\mathrm{CO}_{2}, 3^{\circ} \mathrm{C}$.

To check if the transfection was successful a coverslip was removed and placed on a slide and checked for fluorescence using a GFP filter. If transfection was successful the remaining cover slips were used to observe cells under confocal scanning laser microscopy (CSLM).

\subsection{Results}

\subsection{Results Preamble}

In order to accomplish thesis objectives, western blot analysis is a critical technique for determining the levels of Akt activation. To ensure equal loading of samples, all samples were analyzed for total Akt content by immunoblot with anti Akt antibody (T-Akt). The phosphorylated Akt signal was determined by immunoblotting for Akt phosphorylated (P-Akt) at serine 473 using an antibody 
specific to the phosphorylated serine 473 on Akt. There are a number of variables which were found to impact the phosphorylation of Akt. Early results forced a shift in experimental design to help understand some of the confounding variables. These include the effect of exposing epithelial cells to different serum amounts for varying lengths of time. The integrated density (I.D.) of the western blot bands were measured using ImageJ program (http://rsb.info.nih.gov/ij/index.html) and used to compare the band intensities. The band intensities of each western blot were normalized to the strongest band and compared for each blot independently.

\subsection{Akt Activation by EPEC Infection}

Akt phosphorylation was assayed over a time course of EPEC infection. When HEp-2 cells were grown in 10\% FBS for 2 days prior to infection western blot analysis of the EPEC infected samples showed P-Akt signal at 30mins, $1 \mathrm{~h}$ and the signal disappears after $2 \mathrm{~h}$ (Figure 6A). When HEp-2 cells were serum starved for $24 \mathrm{~h}$ prior to infection western blot analyses of the samples showed no P-Akt signal (Figure 6B).

A

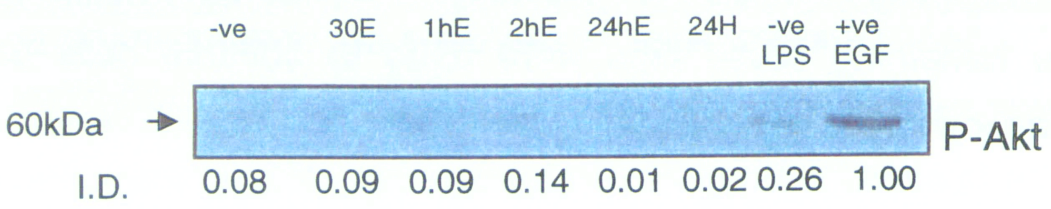




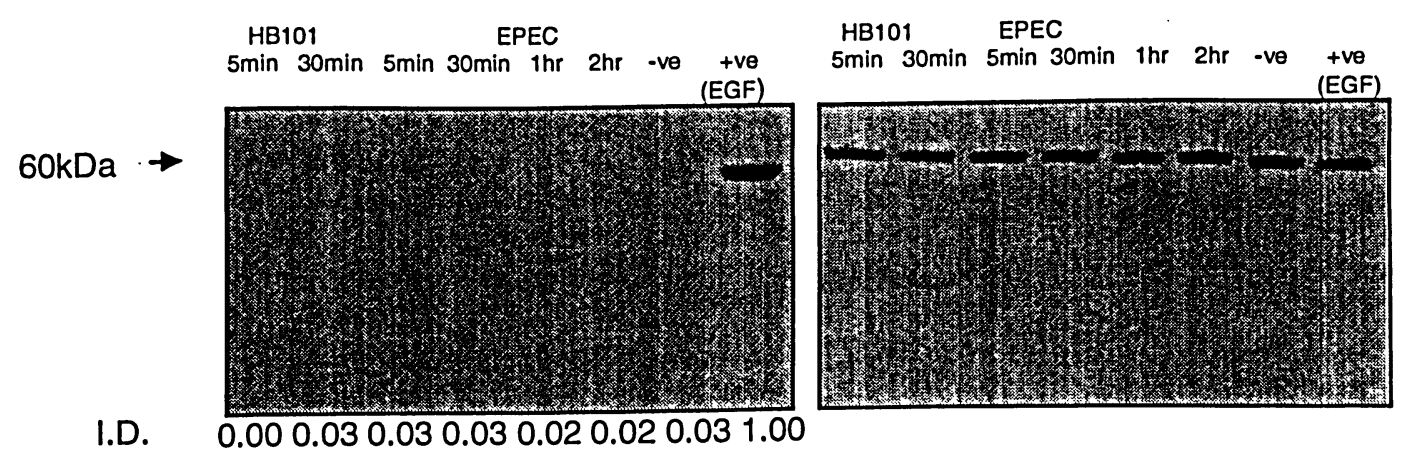

Figure 6: EPEC Infection Induces Phosphorylation of Akt in Serum.

HEp-2 cells were infected with EPEC over an infection time course and resolved on $13 \%$ SDSPAGE gel, transferred to nitrocellulose and probed with rabbit polyclonal anti-phospho-Ser-473Akt (P-Akt) and rabbit polyclonal anti-Akt (T-Akt). (A) 2 days in 10\% FBS prior to infection (B) serum staved for $24 \mathrm{~h}$ prior to infection. Positive controls were $100 \mathrm{ng} / \mathrm{mL}$ EGF treated cells, negative controls were EMEM treated only. The integrated densities for each of the bands (ID) are shown underneath the blots.

\subsection{Akt Activation by Lipopolysaccharide}

\subsubsection{Lipopolysaccharide Time Course}

In order to determine if and when LPS induced the best P-Akt signal a time course was done. Figure 7 shows that after $1 \mathrm{~h}$ of LPS incubation there is a prominent P-Akt band when adding 100ng/mL LPS to HEp-2 cells. There was a P-Akt signal detected with other incubations times, however $1 \mathrm{~h}$ was chosen due to its greater intensity.
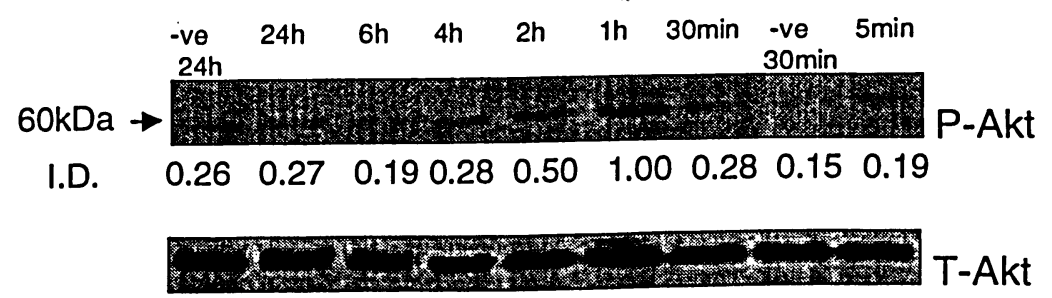

Figure 7 LPS Time Course Using 100ng/mL LPS.

HEp-2 cells were treated with $100 \mathrm{ng} / \mathrm{mL}$ LPS over a time course and total cell lysates were resolved on 13\% SDS-PAGE gel, transferred to nitrocellulose and probed with rabbit polyclonal anti-phospho-Ser-473-Akt (P-Akt) and rabbit polyclonal anti-Akt (T-Akt). The integrated densities for each of the bands (ID) are shown underneath the blots. 


\subsubsection{Lipopolysaccharide Dose Response}

The $1 \mathrm{~h}$ incubation time had been determined to elicit a strong P-Akt signal from 100ng/mL LPS (Figure 7); however the optimal dose needed to be determined. Figure 8 demonstrates that there is a strong P-Akt response to LPS at $10 \mathrm{ng} / \mathrm{mL}$. There are strong bands at other LPS concentrations, however it was important to choose a concentration that would not overwhelm minor intensity changes when looking at EPEC infection.

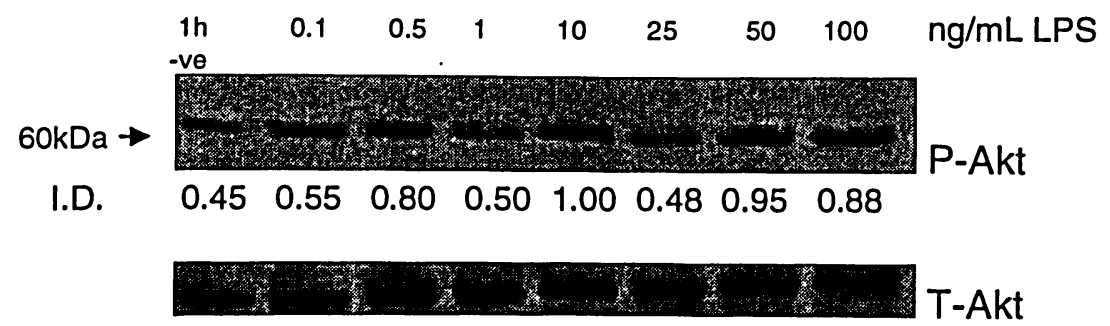

Figure 8 LPS Dose Response.

HEp-2 cells were treated with various LPS concentrations $(\mathrm{ng} / \mathrm{mL})$ over $1 \mathrm{~h}$ incubations. The whole cell lysates were resolved on 13\% SDS-PAGE gel, transferred to nitrocellulose and probed with rabbit polyclonal anti-phospho-Ser-473-Akt (P-Akt) and rabbit polyclonal anti-Akt (T-Akt). The integrated densities for each of the bands (ID) are shown underneath the blots.

\subsection{Akt Activation by EPEC infection with LPS}

\subsubsection{Effect of No Serum}

Akt activation was not shown to occur in the absence of serum (Figure 6, B). The dose response and time course for LPS gave the best Akt phosphorylation signal at $10 \mathrm{ng} / \mathrm{mL}$ LPS after $1 \mathrm{~h}$ of incubation (Figure 7,8 ). To test the effect of EPEC infection on Akt phosphorylation with and without LPS added, the cells were serum starved for $18 \mathrm{~h}$ prior to infection. The following infection experiments in serum free media contradicted the initial results by showing a P-Akt signal after 30min of EPEC infection (Table 4, Experiment 2, 3). 
Table 4: Serum starved cells infected with EPEC and incubated with LPS or EGF.

Drow Treatment: Cells serum starved $18 \mathrm{~h}$ prior to

2. 7 . W infection with and without EGF or LPS
EPEC
Infection
LPS
EGF
Time
$10 \mathrm{ng} / \mathrm{mL} \quad 100 \mathrm{ng} / \mathrm{mL}$

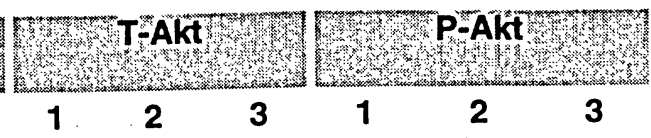

(1h)

(10mins)

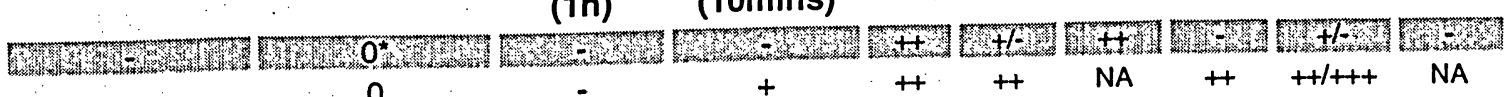

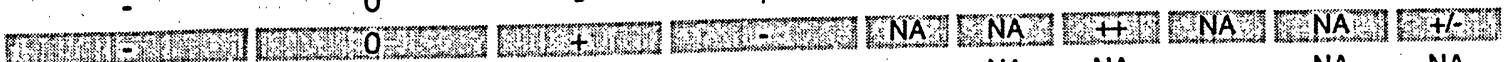
$+\quad 5$ mins $\quad-\quad+\quad$ NA NA $\quad-\quad$ NA NA

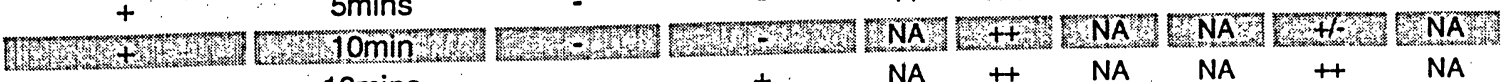
$+\quad 10$ mins $+\quad+$ NA + NA NA + NA

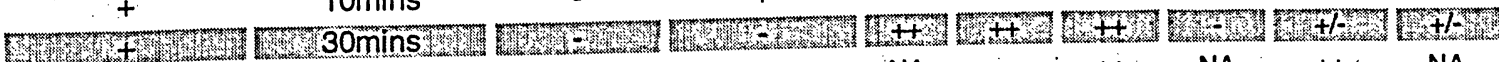
$+\quad$ 30mins $+\quad+\quad$ NA $+\cdots++$ NA + NA

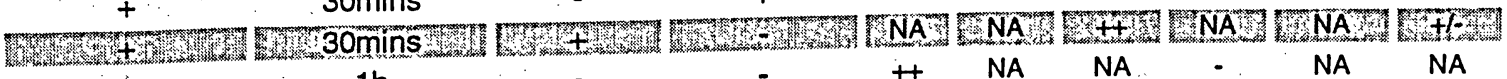

$+\quad \cdot 1 \mathrm{~h} \quad \ldots \quad+\quad \mathrm{NA}$ NA $\quad \cdots$ NA NA

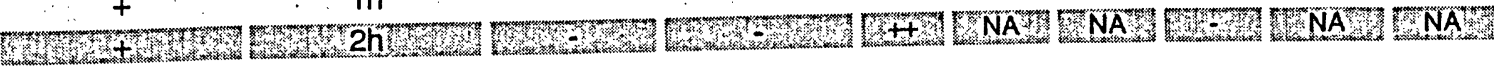

* EPEC infection followed by $1 \mathrm{~h}$ EMEM incubation NA Data not available

Table 5 shows an intermediate Akt phosphorylation signal at 1h EPEC infection followed by $1 \mathrm{~h}$ of EMEM incubation. Wortmannin, a known inhibitor of PI3K signaling was used to ensure that the signal observed was in fact PI3K dependent (100nM Wortmannin for $2 \mathrm{~h}$ ). Since there was a P-Akt signal elicited in the presence of serum, fresh $10 \%$ FBS was added for 1 h to see if its effects were additive to the LPS signal. The addition of LPS after EPEC infection showed no additive affect of the EPEC infection P-Akt signal (Table 5, Experiment 2).

As demonstrated in Figure 9, there is no additive effect for EPEC infection and LPS in the absence of serum. The positive controls using $10 \mathrm{ng} / \mathrm{mL}$ or $100 \mathrm{ng} / \mathrm{mL}$ did not elicit any P-Akt signal at all in the absence of serum. The addition of fresh $10 \%$ FBS induces a distinct P-Akt band, which is enhanced by the addition of $10 \mathrm{ng} / \mathrm{mL}$ LPS. 
Table 5: Serum starved cells infected with EPEC and/or incubated with LPS, serum or wortmannin.

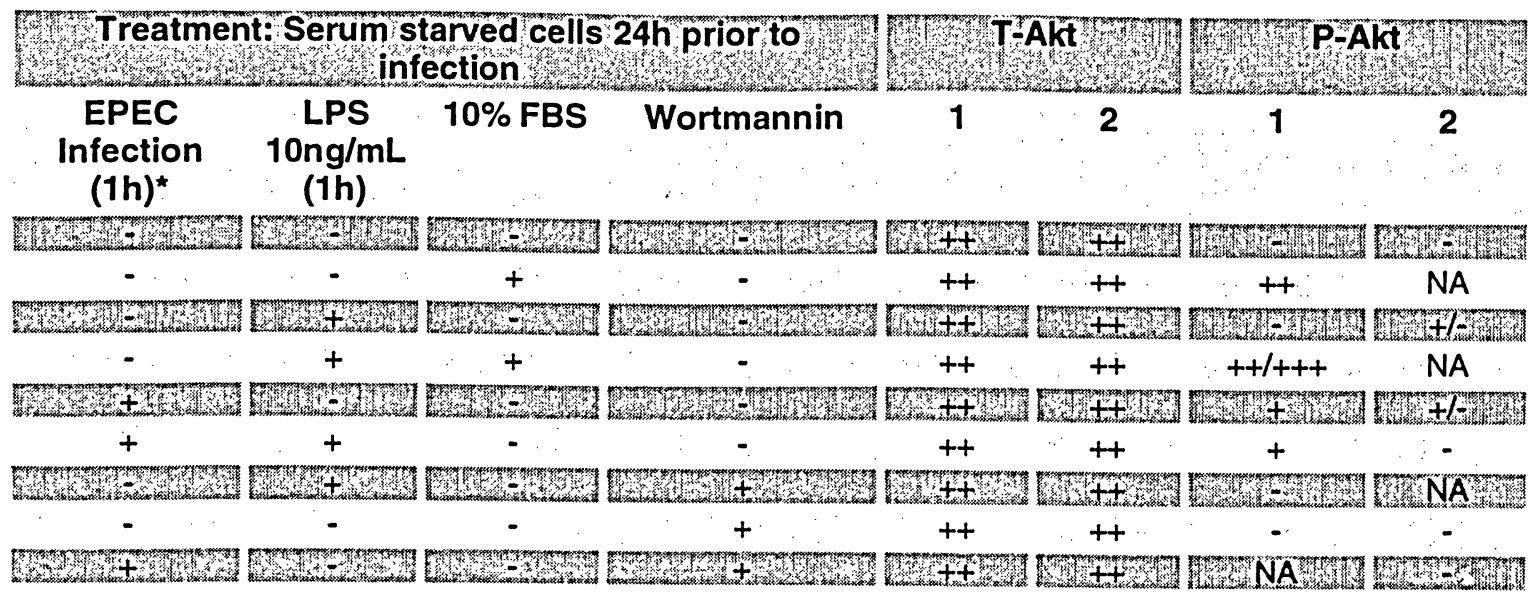

* EPEC infection followed by $1 \mathrm{~h}$ EMEM incubation NA Data not available
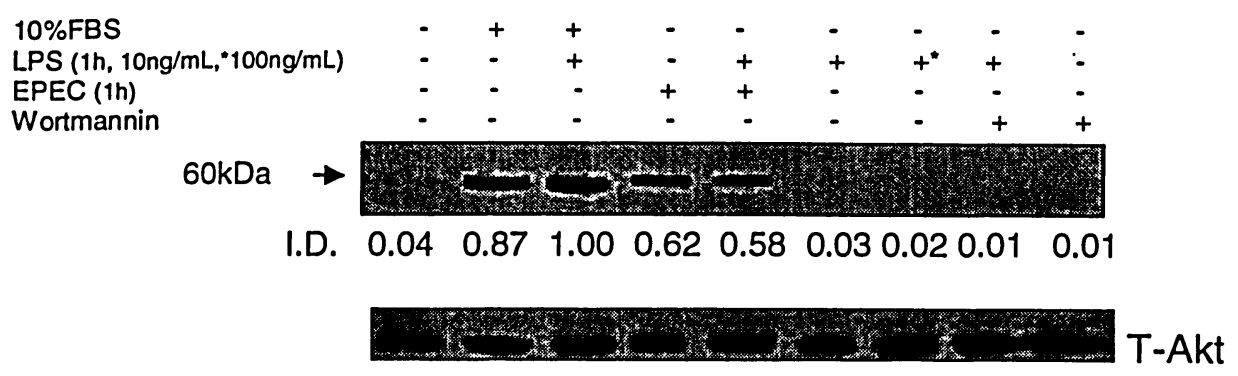

Figure 9: EPEC induces Akt Phosphorylation in Serum Starved cells

HEp-2 cells were treated with various combinations of EPEC, LPS, serum and wortmannin. The whole cell lysates were resolved on 13\% SDS-PAGE gel, transferred to nitrocellulose and probed with rabbit polyclonal anti-phospho-Ser-473-Akt (P-Akt) and rabbit polyclonal anti-Akt (T-Akt). The integrated densities for each of the bands (ID) are shown underneath the blots.

Since the LPS signal was faint or nonexistent in the absence of serum further experiments were done to check the influence of serum on LPS activation of Aktl. Figure 10 shows that the LPS signal is absent except when a high concentration of LPS is used in the incubations. The only prominent P-Akt signal occurs at $500 \mathrm{ng} / \mathrm{mL}$ LPS. 

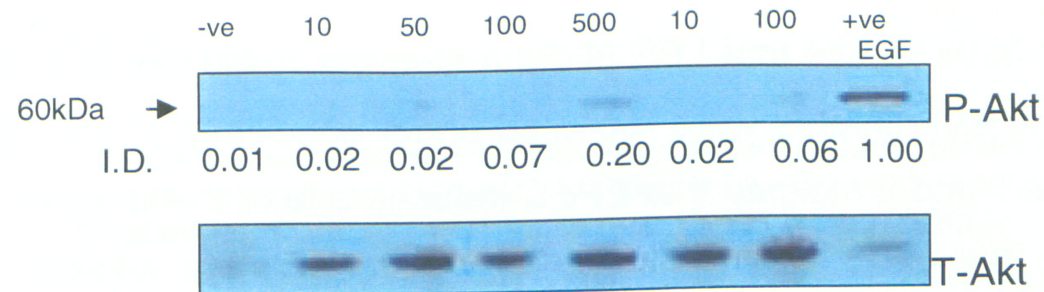

\section{Figure 10: LPS Induces Weak Akt Phosphorylation in Serum Starved Cells.}

The HEp-2 cells were serum starved for $24 \mathrm{~h}$ then treated with various LPS concentrations for $1 \mathrm{~h}$. The whole cell lysates were resolved on 13\% SDS-PAGE gel, transferred to nitrocellulose and probed with rabbit polyclonal anti-phospho-Ser-473-Akt (P-Akt) and rabbit polyclonal anti-Akt (TAkt). The integrated densities for each of the bands (ID) are shown underneath the blots.

The HEp-2 cells had different reactions to EPEC infection and LPS treatment when under different conditions of serum. Figure 11 below demonstrates that serum starved cells have a fainter signal than those in serum.
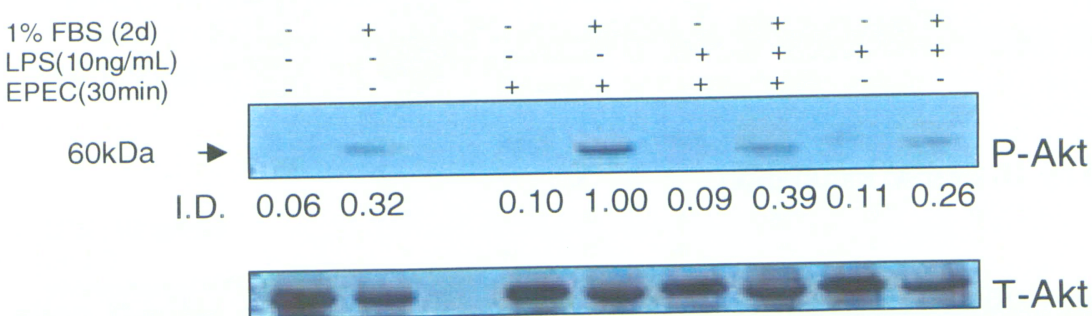

Figure 11: Serum Affects the Induction of PI3K by EPEC Infection and LPS.

HEp-2 cells were either serum starved (18h) or serum fed for $2 \mathrm{~d}$ prior to $30 \mathrm{~min}$ EPEC infection or $1 \mathrm{~h}$ LPS treatment. The whole cell lysates were resolved on $13 \%$ SDS-PAGE gel, transferred to nitrocellulose and probed with rabbit polyclonal anti-phospho-Ser-473-Akt (P-Akt) and rabbit polyclonal anti-Akt (T-Akt). The integrated densities for each of the bands (ID) are shown underneath the blots.

These results indicate that LPS is more effective in eliciting a P-Akt signal in the presence of serum and were the driving force behind the following experiments where cells were in $1 \%$ and $10 \%$ FBS during various treatments. 


\subsubsection{Effect of 1\% Fetal Bovine Serum}

Due to the previous results that LPS elicits a stronger P-Akt signal in the presence of serum the experiments were repeated under conditions of $1 \%$ FBS serum. Table 6, trials 1 and 2 indicate that EPEC induced a faint P-Akt signal at $30 \mathrm{mins}$ and $1 \mathrm{~h}$ and this effect was minimally enhanced with the addition of $10 \mathrm{ng} / \mathrm{mL}$ LPS.

Table 6: Cells incubated in 1\%FBS prior to infection and incubation with LPS. Total and phosphorylated Akt antibodies used for western blot analyses.

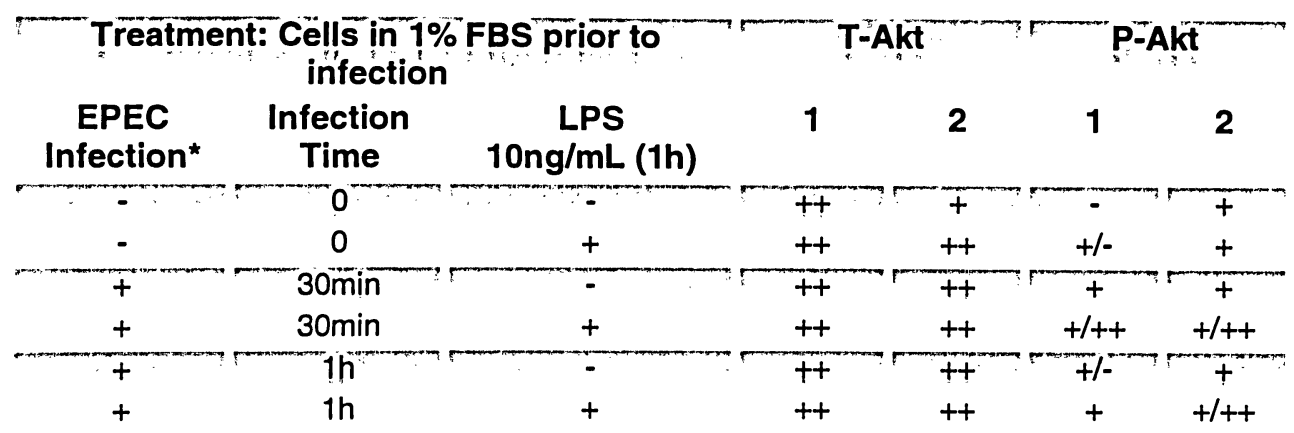

* EPEC infection followed by $1 \mathrm{~h}$ EMEM incubation

To further explore the effects of EPEC infection and LPS on HEp-2 cells more controls were introduced. Table 7 , trial 1 shows that there is a P-Akt signal when $1 \%$ FBS is added to the cells and an additive effect when $10 \mathrm{ng} / \mathrm{mL}$ LPS is added to the media. EPEC also induced a P-Akt signal in experiment 2 and this signal was not enhanced when infection was followed by $1 \mathrm{~h}$ EMEM $+10 \mathrm{ng} / \mathrm{mL}$ LPS incubation. However, when EPEC infection was followed by $10 \mathrm{ng} / \mathrm{mL}$ LPS addition to infection media, there was an increased P-Akt signal.

Figure 12 is a direct representation of trial 2 in Table 6. EPEC induces a P-Akt signal after $1 \mathrm{~h}$ of infection and that signal is unchanged when infection is followed by $1 \mathrm{~h}$ incubation in EMEM+10ng/mL LPS (lane 4), however when the LPS is added to the infection media there is an enhancement of the signal. It is considered an additive effect since the LPS controls show no signal when 
incubated in EMEM alone but when added to same infection media there is a $\mathrm{P}$ Akt signal.

Table 7: Cells incubated in 1\% FBS prior to EPEC, LPS, serum or wortmannin treatment. Total and Phosphorylated Akt antibodies used for western blot analyses
Treatment: $1 \%$ FBS $24 \mathrm{~h}$ prior to infection
T-Akt
P-Akt
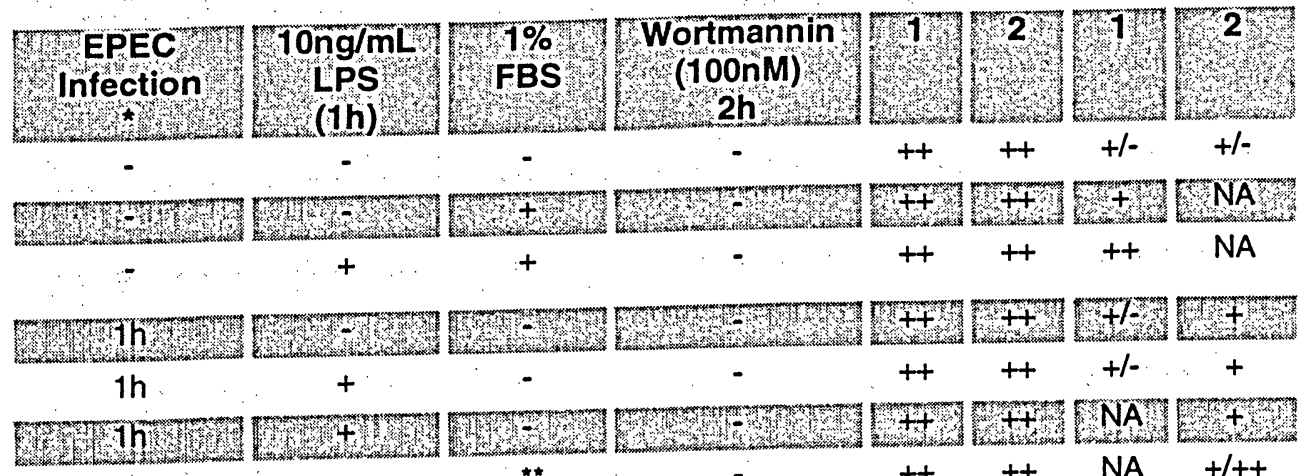

1h
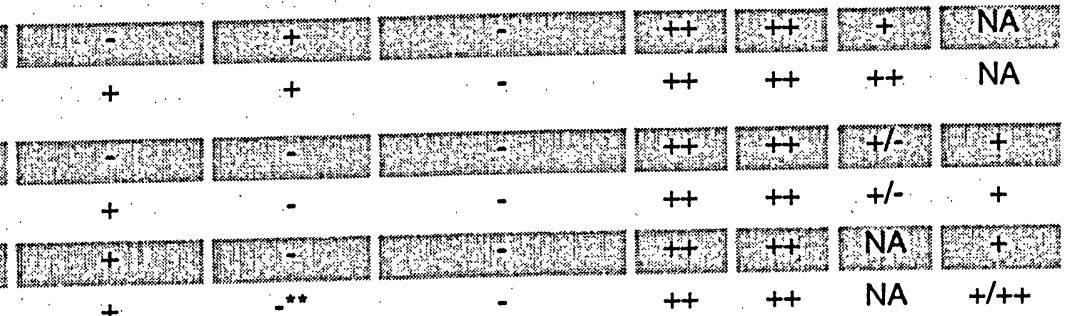

+++++ NA
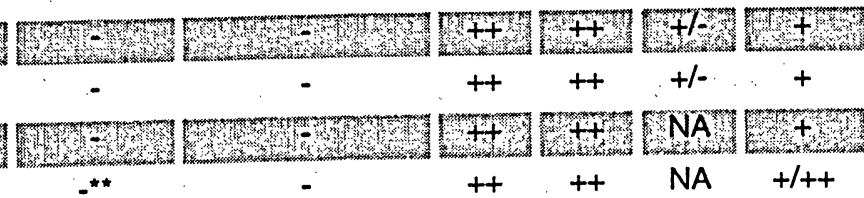

$++\quad+$ + $\quad+$

* EPEC infection followed by $1 \mathrm{~h}$ EMEM incubation

** After $1 \mathrm{~h}$ EPEC infection LPS was added to infection media

NA indicates data not available
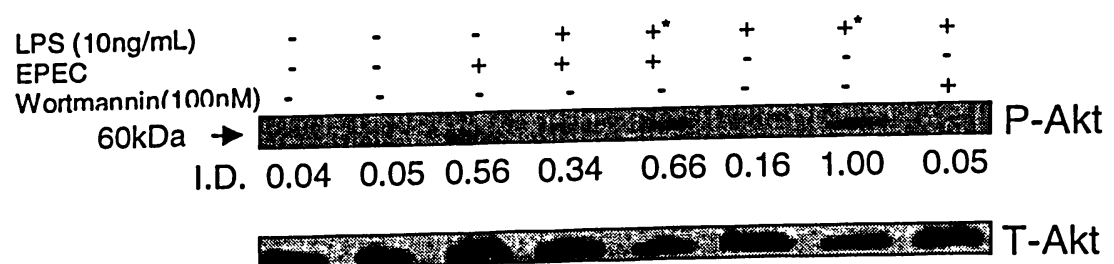

* LPS added to EPEC infection or 24h old serum media instead of EMEM

Figure 12: EPEC Infection Induces Phosphorylation of Akt in HEp-2 Cells in 1\% FBS.

The whole cell lysates were resolved on 13\% SDS-PAGE gel, transferred to nitrocellulose and probed with rabbit polyclonal anti-phospho-Ser-473-Akt (p-Akt) and rabbit polyclonal anti-Akt ( $T$ Akt). The integrated densities for each of the bands (ID) are shown underneath the blots.

\subsubsection{Effect of $10 \%$ Fetal Bovine Serum}

To further investigate EPEC infection, HEp-2 cells were incubated in $10 \%$ FBS for at least $24 \mathrm{~h}$ prior to infection. Table 8 shows that in the presence of $10 \%$ FBS EPEC induces a P-Akt signal at 30mins that fades after $2 \mathrm{~h}$ of infection. 
Table 8: Cells Incubated in 10\% FBS Prior to EPEC infection or LPS Treatment.

Western blot analyses using total and phosphorylated Akt antibodies.

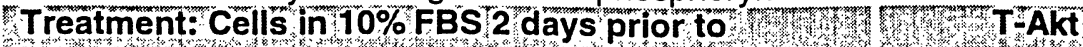

infection

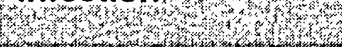

EPEC Infection Infection Time

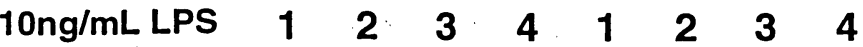

(1hr)

篻W

- $0+++N A N A+\%+N A N A$

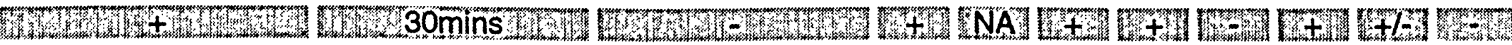

$+30 \mathrm{mins}+{ }_{+} \mathrm{NANA}+\mathrm{NA} N \mathrm{NA}$

Ther

$+2 \mathrm{~h}+{ }_{-}+\mathrm{NA}+\mathrm{NA} \cdot++\mathrm{NA}$

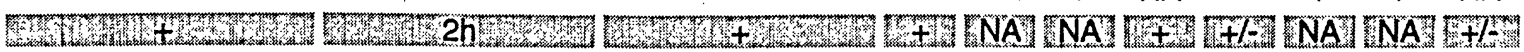

$+4 h \quad+-\quad N A N A+N A N A N A+\%$ NA

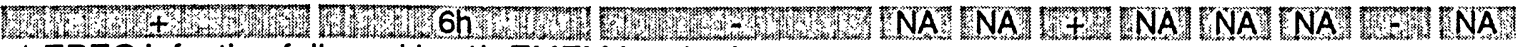

* EPEC infection followed by ih EMEM incubation

NA indicates data not available

To fully elucidate the effects of LPS and EPEC infection on HEp-2 cells more controls were introduced to the experiment. Table 8 demonstrates the difference between LPS treatment in the presence and absence of serum. From these experiments it is evident that serum induces the P-Akt signal which is enhanced with LPS and absent when cells are treated with wortmannin, a known PI3K inhibitor. LPS alone in EMEM does not elicit a P-Akt signal, however when LPS is added to the $2 \mathrm{~d}$ old $10 \%$ FBS media there is a significant P-Akt signal.

EPEC infection elicited a P-Akt signal as well after $1 \mathrm{~h}$ and this signal was enhanced only when LPS was added to the infection media not when LPS was added in EMEM. The EPEC signal was also absent when cells were treated with wortmannin. 
Table 9: Cells incubated in 10\% FBS 2 days prior to LPS, serum or EPEC infection Treatments.

Western blot analyses of EPEC infected HEp-2 cells using total Akt to measure equal loadings and P-Akt to measure the induction of PI3K pathway.

Treatment: Cells in 10\% FBS 2 days prior to w w

treatment

EPEC

LPS $\quad 10 \%$

Infection *

$10 \mathrm{ng} / \mathrm{mL}$

FBS

(1h) (2h)

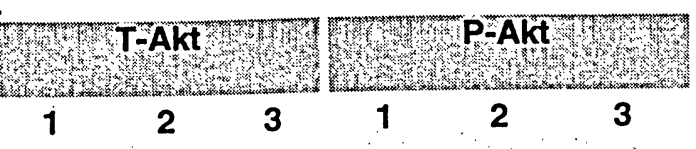

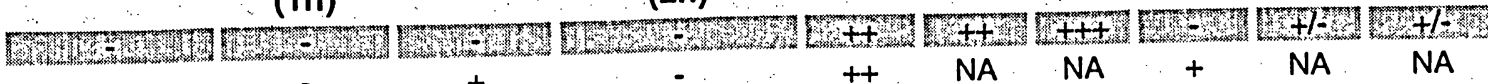
$->-\ldots+$

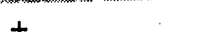
NA. NA

WrTw

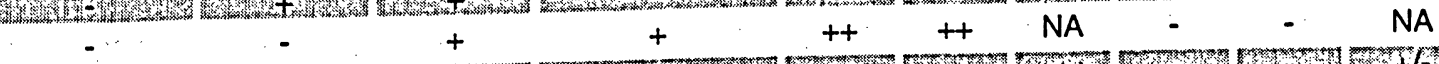
J

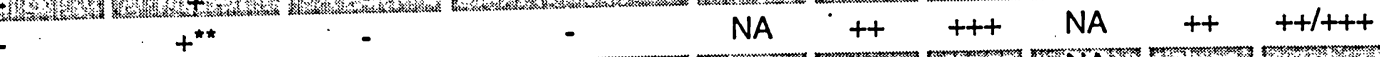

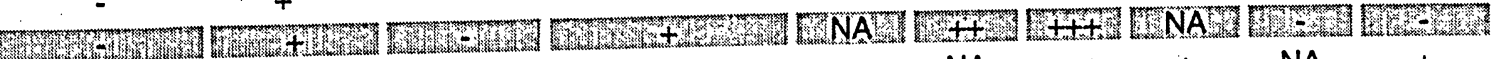
$1 \mathrm{~h}$
-
$+\quad++\quad N A$
$\mathrm{NA}++++\mathrm{NA}+$

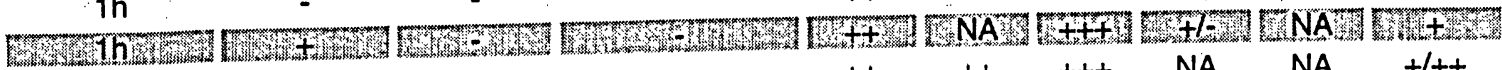

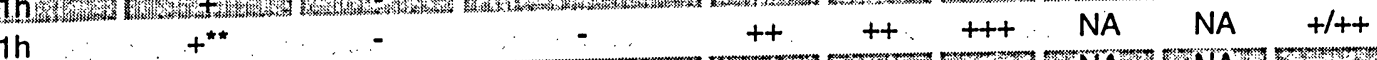

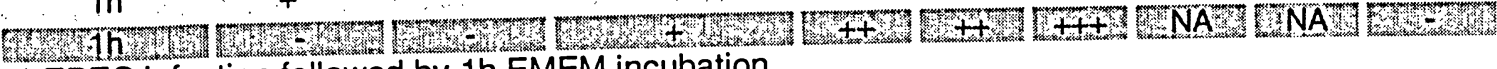

* EPEC infection followed by $1 \mathrm{~h}$ EMEM incubation

** LPS was added to the infection media or $24 \mathrm{~h}$ old $10 \%$ FBS instead of EMEM

NA indicates data not available

Figure 13 below is a direct representation of experiment 22 from Table 8. It appears that $10 \mathrm{ng} / \mathrm{mL}$ LPS added to $24 \mathrm{~h} 10 \%$ FBS media had a stronger P-Akt signal than the EPEC+ LPS sample.

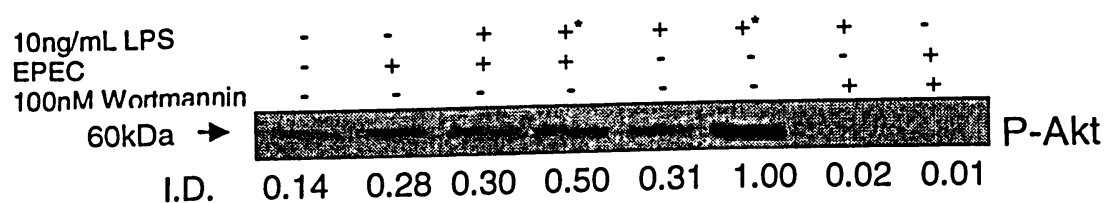

I.D. $\quad \begin{array}{llllllll}0.14 & 0.28 & 0.30 & 0.50 & 0.31 & 1.00 & 0.02 & 0.01\end{array}$

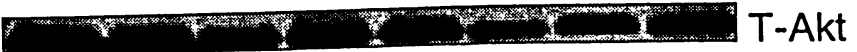

* LPS added to infection media or $24 \mathrm{~h}$ old $10 \%$ FBS media

Figure 13: EPEC Infection Activates PI3K in HEp-2 Cells Incubated in 10\% FBS 2 days Prior to Infection.

The whole cell lysates were resolved on 13\% SDS-PAGE gel, transferred to nitrocellulose and probed with rabbit polyclonal anti-phospho-Ser-473-Akt and rabbit polyclonal anti-Akt. 


\subsection{Other Signaling Proteins}

There are many different signaling proteins that may be activated during EPEC infection. These include both pro-apoptotic signaling proteins such as Bax and anti-apoptotic proteins such as Bcl-2. To elucidate the other signaling pathways that may be activated during EPEC infection Bax, Bcl-2 and Caspase-9 antibodies were used in western blot analyses.

\subsubsection{Bax}

The activation of Bax indicates the 'turning on' of a cell death pathway. When Bax is in high concentration, it continues the death pathway signaling, and when in low concentration indicates a "turning off" of a cell death pathway. An increase in Bax should correlate with a decrease in phosphorylated Akt present. As shown previously EPEC induces Akt phosphorylation and activation between 30 mins and this signal fades after $2 \mathrm{~h}$ of infection. As seen in Figure $13 \mathrm{~A}$, the Bax signal increases at $2 \mathrm{~h}$ and becomes stronger after $6 \mathrm{~h}$ of infection. Figure $13 \mathrm{~B}$ also demonstrates the stronger signal at $2 \mathrm{~h}$ of EPEC infection. This correlates with the time point at which the phosphorylated Akt bands disappear as seen in Figure 6.

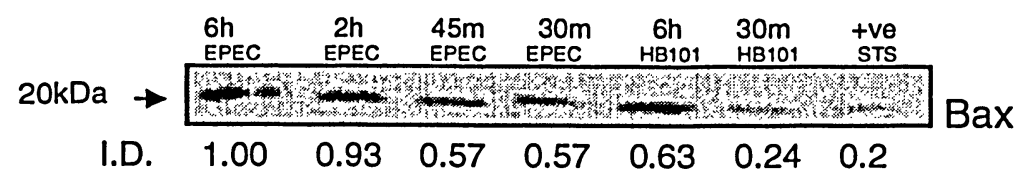

Figure 14 Bax Levels Increase After $2 \mathrm{~h}$ of EPEC Infection.

The whole cell lysates were resolved on 12.5\% SDS-PAGE gel, transferred to nitrocellulose and probed with rabbit polyclonal anti-Bax. $15 \mathrm{mM}$ Staurosporine (STS) was used for the positive control.

The integrated density values show that EPEC infection increases the concentration of Bax when compared to HB101 infection, showing a more pathogenic response. 


\subsubsection{Caspase-9}

There are various cell death signaling pathways one of which involves the caspase cascade. Activation of the caspase death pathway involves Caspase-9. When caspase- 9 is activated, it continues the cascade but also increases in concentration. The Caspase- 9 antibody used in these experiments identifies both procaspase-9 (inactive form $\sim 45-50 \mathrm{kDa}$ ) and the p10 subunit which is formed after Caspase- 9 is cleaved to its active form. Figure 15 indicates that there is no change in the procaspase-9 or p10 concentration over the time course of EPEC infection.

A $\begin{array}{llllllll}6 h & 4 h & 2 h & 45 m & 6 h & 4 h & 45 m & \text { tve } \\ \text { EPEC } & \text { EPEC } & \text { EPEC } & \text { EPEC } & \text { HB101 } & \text { HB101 } & \text { HB101 } & \text { STS }\end{array}$

I.D.
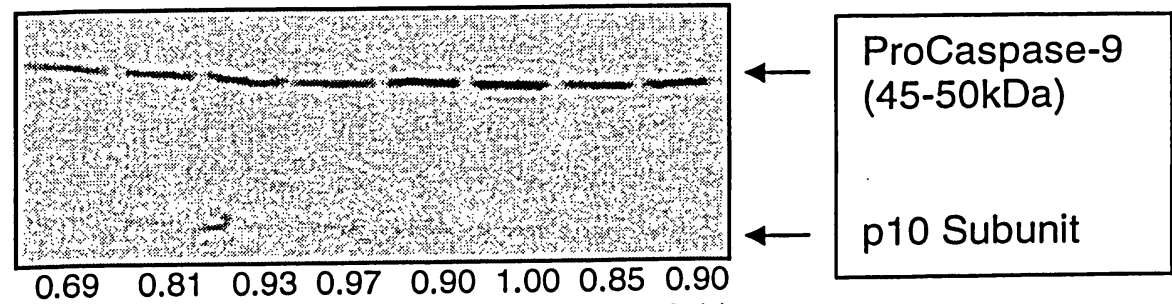

0.12

0.10

0.18

0.14

$\begin{array}{llll}0.18 & 0.12 & 0.17 & 0.11\end{array}$

B
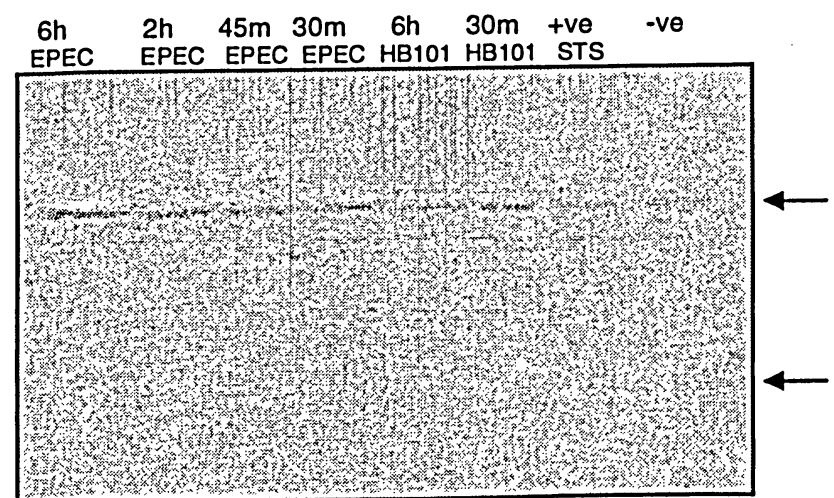

\begin{tabular}{|l|}
\hline ProCaspase-9 \\
(45-50kDa) \\
p10 Subunit \\
$(10 \mathrm{kDa})$
\end{tabular}

I.D.

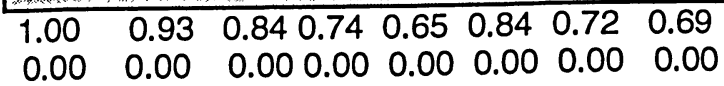

Figure 15 Caspase-9 Activation Does Not Occur Within 6h of EPEC Infection.

The whole cell lysates were resolved on 12.5\% SDS-PAGE gel, transferred to nitrocellulose and probed with rabbit polyclonal anti-Caspase-9. Staurosporine (STS) was used as the positive control. 


\subsubsection{Bcl-2}

$\mathrm{Bcl}-2$ is an anti-apoptotic protein that protects the mitochondria from cytochrome $\mathrm{c}$ release. When apoptosis is induced there is a down regulation of Bcl-2 concentration (Tikhomirov \& Carpenter, 2005). Figure 16 indicates that Bcl-2 levels decrease as the EPEC infection progresses. It appears that at $30 \mathrm{mins}$ there is the strongest band that slightly decreases over time. Figure 16 also indicates a faint band for the HB101 control, which is surprising since the HB101 strain is noninvasive and nonpathogenic. This result may be confounded by the differential widths of bands.

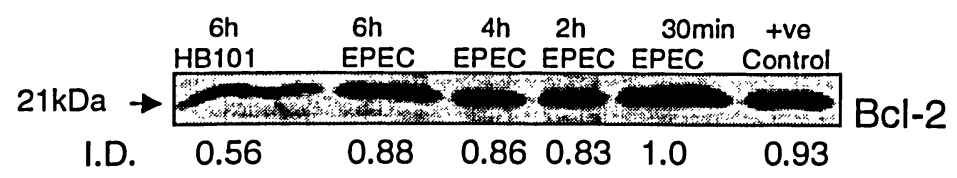

Figure $16 \mathrm{Bcl}-2$ Levels Decrease as EPEC Infection Progresses The whole cell lysates were resolved on 13\% SDS-PAGE gel, transferred to nitrocellulose and probed with donkey polyclonal anti-Bcl2. Staurosporine (STS) was used as the positive control

\subsection{Discussion}

\subsection{Effect of EPEC infection on Akt phosphorylation}

The activation of PI3K signaling was measured by western blot analyses using the P-Akt antibody that identifies Akt phosphorylated at ser 473 . The EPEC time course experiments showed that the PI3K pathway was activated during infection at $30 \mathrm{mins}, 1 \mathrm{~h}$ and $2 \mathrm{~h}$ in the presence of serum then faded. In the absence of serum it was initially thought that no Akt activation occurred but those results were proven to be false in later experiments.

It has been shown by Celli et al., (2001), that EPEC blocks its internalization through inhibition of PI3K and specifically inhibition of Fc $\gamma$ receptor in macrophages. They saw activation of PI3K at $5 \mathrm{mins}$ and that signal faded after 30mins infection with wildtype EPEC (Celli et al., 2001). However, in 
previous studies, the onset of antiphagocytosis of EPEC occurred 2-3h after the addition of bacteria to macrophages and this was thought to be due to the time needed for EPEC to express virulence factors (Celli et al., 2001). The time it takes for expression of virulence factors is thought to be shortened by culturing bacteria in DMEM at $3^{\circ} \mathrm{C}, 5 \% \mathrm{CO}_{2}$ prior to infection (Celli et al., 2001).

In contrast to the research findings of Celli, Quitard et al (2006) found that loss of phosphorylation of Akt in macrophages during EPEC infection was not due to inhibition of PI3K. They used quadruple mutant and single mutant strains for Map, Tir, EspF and intimin and were unable to inhibit PI3K-dependent uptake but they still elicited transient P-Akt signal. This therefore indicates that EPEC employs alternative non-intimin-mediated signaling to induce the dephosphorylation of Akt (Quitard et al., 2006).

Another important finding of this research group is that the EspF inhibition of PI3K uptake was independent of mitochondrial targeting (Quitard et al., 2006). EspF has been shown to target the mitochondria and disrupt organelle membrane potential (Nougayrede \& Donnenberg, 2004). Quitard et al (2006) used an EspF mutant lacking the mitochondrial targeting sequences (MTS) to test the role of mitochondrial targeting during inhibition of bacterial internalization. The EspF protein accumulated in the cytoplasm and also retained its ability to inhibit bacterial internalization (Quitard et al., 2006).

In this study EPEC was pre-induced in HEPES buffered DMEM for 2.5-3h, and this has been reported to activate expression of type III secretion system and bacterial effectors (Celli et al., 2001). However the activation of PI3K and thus Akt did not occur until $30 \mathrm{mins}$ and lasted until $2 \mathrm{~h}$ after infection. The P-Akt signal was seen in both serum starved and serum fed cultures discounting serum constituents as a factor. This observed difference when compared with findings reported in the literature may also be accounted for by the different tissue types used and their function. Much of the literature when looking at phosphorylation 
of Akt involves the use of macrophages. Macrophages are professional phagocytes and it is their very nature to internalize invaders quickly. In this study epithelial cells were used for the study of Akt. Epithelial cells are specialized to maintain complex secretory and absorptive functions with the luminal environment but are non-phagocytic (Vallance \& Finlay, 2000). In studies with invasive species such as Shigella, it has been shown that infection of macrophages differs from epithelial cell infection in that macrophages will undergo apoptosis-like death as early as $1 \mathrm{~h}$ after infection while epithelial cells remain viable for up to $4 \mathrm{~h}$ after infection (Mantis et al., 1996; Lucchini et al., 2005).

\subsection{Effect of Lipopolysaccharide and Serum on Akt Activation}

LPS is a component of the capsule of gram negative bacteria and has been previously shown to elicit phosphorylation of Akt, the downstream effector of PI3K (Pengal et al., 2006). An LPS time course demonstrated that it did indeed activate the PI3K signaling pathway in HEp-2 cells by producing a phosphorylated Akt signal in western blot analyses. The most prominent signal occurred at $1 \mathrm{~h}$. The dose response demonstrated that LPS had a strong signal at 10,50 and $100 \mathrm{ng} / \mathrm{mL}$. The $10 \mathrm{ng} / \mathrm{mL}$ concentration was chosen because it was strong but not the highest concentration so not to overpower any EPEC signal that might have been present when applied in consecutively.

A surprising finding during these experiments was that LPS did not elicit a strong phosphorylated Akt signal in the absence of serum except at the highest concentrations tested. In general when preparing cells for infection the cells are serum starved prior to infection. It has been shown that macrophages serum starved prior to LPS treatment still activate Akt (Salh et al., 1998; Pengal et al., 2006; Quitard et al., 2006). However, Pengal et al (2006) also noted that macrophages deficient in inositol phosphatases SHIP and PTEN have elevated levels of Akt activation. When monocyte THP-1 cells were incubated with LPS and $1 \%$ serum there was also phosphorylated Akt signal (Patel \& Corbett, 2004). 
In the presence of $10 \%$ serum P-Akt signals were observed in neutrophils as well as macrophages (Klein et al., 2001; Monick et al., 2001). The phosphorylation of Akt by LPS treatment has not been observed in serum starved epithelial cells

Subsequent experiments in the presence of serum demonstrated that a strong phosphorylated Akt signal could be obtained. The known receptor for LPS is TLR4. TLRs are known to require co-receptors for bacterial recognition and modulation of downstream signaling and LPS requires MD-2, LBP and CD14 (Akashi-Takamura \& Miyake, 2006) The extracellular domain of TLR4 is associated with MD-2, which directly interacts with LPS (Akashi-Takamura \& Miyake, 2006). Many cells don not express membrane bound CD14 (mCD14) instead they use soluble CD14 (sCD14) (Dundendorfer et al., 2004).

CD14 is present in normal serum as a soluble protein or on the surface of monocyte cell surfaces as a glycosylphosphatidylinositol (GPI) anchored protein and its binding with LPS triggers signaling (Goldblum et al., 1994; Bannerman \& Goldblum, 2003; Akashi-Takamura \& Miyake, 2006). CD14 alone does not have transmembrane domain and is incapable of intrinsic signaling (Lien et al, 2000). LPS receptor antagonists have been shown to inhibit the effects of LPS at concentrations too low to block LPS binding to CD14 suggesting that receptor inhibition is not due to blockade of CD14 (Lien et al., 2000).

LPS signaling still occurs in the absence of CD14 however the TRAMTRIF pathway is not activated without it (Akashi-Takamura \& Miyake, 2006). In the presence of serum, LPS elicits a strong P-Akt signal, which implicates serum as somehow being involved in LPS binding. This may also be interpreted as indicating the existence of 'cross-talk' amongst receptors.

$\mathrm{PI} 3 \mathrm{~K}$ signaling is involved in many processes including cell proliferation. The purpose of serum is to provide growth factors for cells to grow. Therefore it is logical that the addition of fresh serum alone elicits a strong P-Akt signal in 
HEp-2 cells. Most researchers studying the phosphorylation of Akt, serum starve their cell lines prior to treatment to reduce basal levels of P-Akt and prevent false positives. After $2 \mathrm{~d}$ of incubation in serum media, HEp-2 cells contain no significant $\mathrm{P}$-Akt signal and therefore should be in an equivalent state.

Intuitively the serum starvation of cells should have an effect on their overall health and susceptibility to treatment. It has been shown that in confluent cultures, serum starvation induced an increase in mitochondrial viability (Takeda et al., 2002). Takeda et al., (2002) also noted that less confluent cell cultures showed depressed mitochondrial activity after serum starvation. It appears that confluency and serum conditions all play a part in the susceptibility of cells to treatment.

LPS produced by commensal flora is present in the gastrointestinal tract without causing disease (Jacobsen et al., 2005). However, a strong inflammatory response is elicited to LPS when it enters systemic circulation (Jacobsen et al., 2005).

When LPS is added to $2 \mathrm{~d}$ old serum media there is a moderate P-Akt signal. When LPS is added to cells in fresh serum media there is an additive effect between the serum and LPS responses. This response appears to be biologically relevant because prior to breaking of the protective epithelial layer LPS exists in serum free environment and does not elicit an inflammatory response. However once the epithelial barrier is compromised, LPS will exist in an environment rich in serum and induces inflammation signaling. As previously mentioned LPS binding requires LBP, MD-2 and CD14, the last of which has been reported to be missing on some epithelial tissues (Goldblum et al., 1994). There is a soluble CD14 (sCD14) present in normal serum and this molecule can be used by LPS to bind TLR4 (Goldblum et al., 1994). 


\subsection{Effect of EPEC Infection and Lipopolysaccharide on Akt Activation}

In this study EPEC infection and LPS have both been shown to induce phosphorylation of Akt. In the absence of serum, EPEC induced a phosphorylated Akt signal and when LPS was added to the EPEC infected cells with fresh EMEM, there was no enhanced response. This non-affect of LPS in serum free media has been previously explained above.

Table 10 Overview of the Effect of EPEC, LPS and serum on Akt Activation

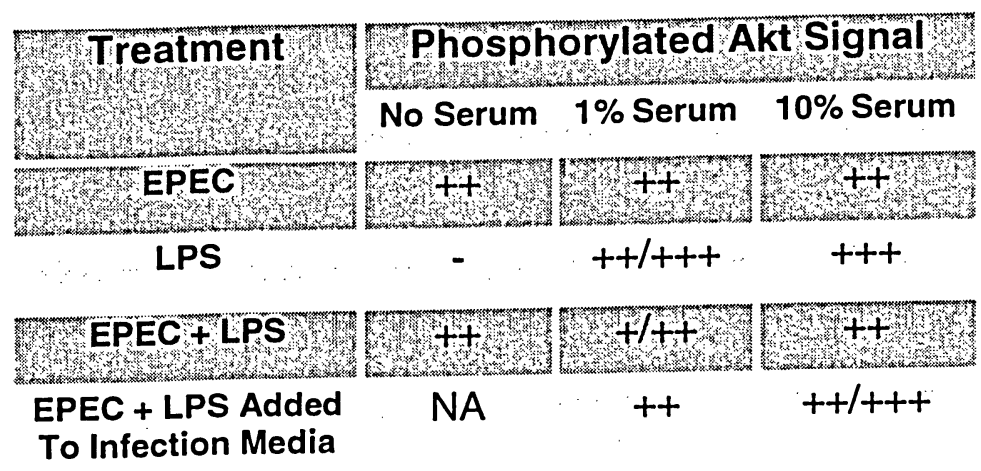

NA indicates data not available

Table 10 shows that in $1 \%$ and $10 \%$ serum experiments, EPEC infection induced phosphorylation of Akt. When LPS was added to the uninfected cells in $2 d$ old serum media instead of EMEM, a P-Akt signal was identified during western blot analyses. When LPS was added to EPEC infection media the resulting signal was stronger than EPEC infected cells alone but slightly weaker than LPS treated cells alone.

This indicates that a higher concentration of P-Akt was present after LPS addition; however, the band was less strong than with LPS alone. This finding remains to be explained; however, there are a few possible explanations for this.

It is possible that because EPEC had already been in the process of infection before the LPS addition the availability of host cell binding sites was 
decreased and therefore no change in the P-Akt signal. This indicates that LPS and EPEC may share the same activation of PI3K signaling. In contrast, EPEC and LPS may use many of the same molecules in the activation of PI3K but that the actual process by which this occurs differs. If this is the case then the signaling events occurring during EPEC infection and LPS addition could present a situation where signaling events cross over. This 'cross-talk' is necessary in the human body for rapid response to incidents of bacterial infection and disease.

There are a few experiments that could be done to help elucidate these results. The addition of LPS was always after EPEC infection. If LPS was added before EPEC it would show either equivalent P-Akt signal to LPS alone now proving that EPEC masks binding sites or uses the same molecules during infection that LPS requires for Akt activation. To test the possible sharing of signaling molecules, after EPEC infection the media could be sterile filtered and re-applied to new cells to see if any Akt is phosphorylated. It would be very interesting to test for and measure the concentration of assessory molecules of LPS and TLR4 to see if there are any changes under these different conditions.

\subsection{Other Signaling proteins}

\subsubsection{Caspase-9}

The other signaling proteins examined in these experiments were done as means to elucidate the possible mechanism of EPEC infection on HEp-2 cells. After a cell death signal, cytochrome $c$ is released from the mitochondria and activates Caspase-9, an important apoptosis initiator in the caspase cascade.

The Caspase- 9 antibody used in these experiments identifies both procaspase- 9 and the p10 subunit that exists once caspase- 9 is activated via cleaving. Once cleaved there will be 2 subunits present, a p35 and a p10 and these subunits should be found in equal amounts in the cell. 
These experiments demonstrated that there were very faint or nonexistent cleaved caspase- 9 products during an EPEC infection time course. These faint bands seen in Figure 15 may be basal caspase- 9 levels present in the tissue culture. As seen in Figure 16 there is no p10 subunit band found. This indicates that caspase- 9 was not activated and a possible alternative death pathway was initialized. However it is also possible that these experiments did not allow the full progression of EPEC infection to occur and longer incubations of greater than $24 \mathrm{~h}$ may be needed. The faint $\mathrm{p} 10$ bands may also indicate incomplete activation of caspase-9.

Quitard et al., (2006) found that the inhibition of PI3K during EPEC infection was not due to the PI3K uptake process and that it was mitochondrialindependent. This finding supports the works of this research thesis since no Caspase- 9 was found during the EPEC infection time course.

Nougayrede \& Donnenberg (2004) did not see any activation of caspase-9 after 1 or $2 \mathrm{~h}$ of EPEC infection. However after $3 \mathrm{~h}$ of EPEC infection they observed trace amounts of caspase- 9 in western blot analyses. Since they also observed caspase-3 (activated via caspase-9 cleavage) in EPEC infected cells it was suggested that caspase- 9 is only activated in concentrations below the threshold of detection. EPEC infection stimulates anti-apoptotic signaling in host cells and thus it is possible that these signals somehow overwhelm the proapoptotic signaling that leads to caspase-9 activation (Nougayrede \& Donnenberg, 2004; Raina et al., 2005).

\subsubsection{Bax}

Bax is a pro-apoptotic protein that is activated in the presence of a cell death signal. Figure 14, shows the concentration levels of Bax increase as the EPEC induced Akt signal begins to fade after $2 h$ of infection. 
It has been found that some cells contain a higher concentration of Bax in general than others and this may explain the basal level of Bax found in the HB101 treated samples. Tikhomirov \& Carpenter (2005) found that there are different levels of Bax found in various cell types. They also found that there is a gradual translocation and accumulation of Bax in EGF-induced apoptosis. Under these conditions Bax will migrate to the mitochondrial outer membrane between 8 and $24 \mathrm{~h}$ and there is no indication of mitochondrial membrane potential (MMP) loss at this time (therefore no cytochrome c loss and no caspase cascade) (Tikhomirov \& Carpenter, 2005).

\subsubsection{Bcl-2}

$\mathrm{Bcl}-2$ is a pro-apoptotic protein that is found in high concentrations when inhibiting apoptosis. In Figure 17 it appears that the levels of $\mathrm{Bcl}-2$ are decreasing as the EPEC infection time course progresses. It is expected that as P-Akt concentrations diminish, Bcl-2 levels will also diminish. However with respect to this research thesis these results remain inconclusive since this experiment has yet to be reproduced.

It was surprising to see in Figure 16 that the HB101 nonpathogenic EPEC strain produced a $\mathrm{Bcl}-2$ band. It is possible that HB101 still induced a Bcl-2 signal because it is still a foreign body in the tissue culture and after $6 \mathrm{~h}$ of incubation may have produced wastes that may have induced a slight signal.

The $\mathrm{Bcl}$ family of proteins are considered the primary protectors of the mitochondrial membrane by regulating its osmotic homeostasis (Vander Heiden et al., 1997; Nougayrede \& Donnenberg, 2004). Even though the HB101 strain is nonpathogenic it may still cause minor changes in the culture media that consequently elicits a Bcl-2 signal. 
The epithelial cell layer has many mechanisms in which it displays tolerance for commensal bacteria (Sansonetti, 2004). Non-pathogenic gram negative bacteria can activate peroxisome-proliferator-activated receptor $\gamma$ (PPAR- $\gamma$ ), which has an anti-inflammatory function and is a negative regulator of NF-KB (Sansonetti, 2004). This cell signaling response may help to explain the HB101 signal present.

\subsection{Summary of Results and Significance}

In this study it was found that EPEC infection induced the phosphorylation of Akt. The phosphorylated Akt signal was first seen at $30 \mathrm{mins}$ and was sustained until $2 \mathrm{~h}$ after infection. Previous studies with macrophages have shown that phosphorylation of Akt occurs as early as 5 mins and disappears 30 mins after infection. The difference observed here in the delayed activation of Akt is likely due to the different cell types used and their native functions.

It is the very nature of macrophages is to react quickly to invaders, while epithelial cells are not professional phagocytes and "allow" the formation of the pedestal. It seems logical for epithelial cells to elicit sustained responses to external stimuli. The epithelial barrier is constantly bombarded with challenges that it must overcome and longer responses may help to ensure their health and integrity.

The detected levels of Bax and Bcl-2 correlated with the phosphorylated Akt levels during EPEC infection. As the levels of P-Akt were decreasing at $2 \mathrm{~h}$ after infection so were the levels of Bcl-2. At this same time, $2 \mathrm{~h}$ after infection Bax levels began to rise. This may indicate the shutting down of the antiapoptotic signaling and the onset of the cell death pathway.

The finding that Caspase-9 was not activated as early as $6 \mathrm{~h}$ after infection was surprising. This finding may indicate there was incomplete activation and 
that longer infection times are needed to observe it. It may also indicate that this is a signaling pathway independent of caspase-dependent cell death.

The results of this study also provide insight into the mechanisms of LPS. The fact that LPS did not induce any signal in the absence of serum is logical and also makes treatments done in the presence of serum more biologically relevant. LPS will not be active in serum free environment such as the protective epithelial barrier. But once LPS has entered into systemic circulation it can induce intense inflammatory responses that may lead to severe infection and septic shock.

In the presence of serum, both EPEC and LPS activate Akt phosphorylation. When EPEC infection is followed by LPS addition the phosphorylated Akt signal increases. However this signal is not completely additive in that it is less intense than LPS alone but more intense than EPEC alone. There are a few reasons as to why this may happen.

When LPS is added to the infection media it is possible that some receptor sites may be unavailable due to the presence of EPEC. These sites may be blocked or the expression of them is decreased in the presence of a pathogen. Another reason could be that EPEC has somehow masked the helper molecule that enables LPS to bind to TLR4 and thus decreased binding occurs.

It is important however to keep in mind that the molecules of these signaling pathways are multi-functional and capable of working together for their own means. So that if a molecule is used or masked by EPEC infection it may be an indication of signaling cross-over.

Boya et al., (2005) proposed that in nutrient depletive conditions there is cross-talk between apoptosis and autophagy signaling pathways. During EPEC infection the amount of nutrients is depleted as the infection continues. EPEC has also been shown to have apoptosis-like features. In this study there was 
little detection of pro-apoptotic proteins until after 2 hours and no caspase-9 detection. Caspase-9 is an indicator of mitochondrial membrane potential loss and is irreversible.

The data of this thesis suggest that there are likely separate sensing mechanisms for EPEC, LPS and serum that are independent but synergistic and that Akt is the integration site of these signaling cascades. This is consistent with other reports that Akt plays a central role in cell signaling (see Figure 17). EPEC triggers PI3K through TTSS facilitated by intimin-Tir binding. LPS is known to trigger PI3K through TLR4 and its complex, while serum has been shown to activate $\mathrm{PI} 3 \mathrm{~K}$ through a serum response factor. When cells were treated with either EPEC, LPS, or serum there was evidence of Akt phosphorylation, which varied in intensity with respect to dose and time. When the cell is treated with various combinations of the three, there is evidence of synergistic signaling at the level of Akt phosphorylation which is sometimes reflected in an additive or augmented signal. 


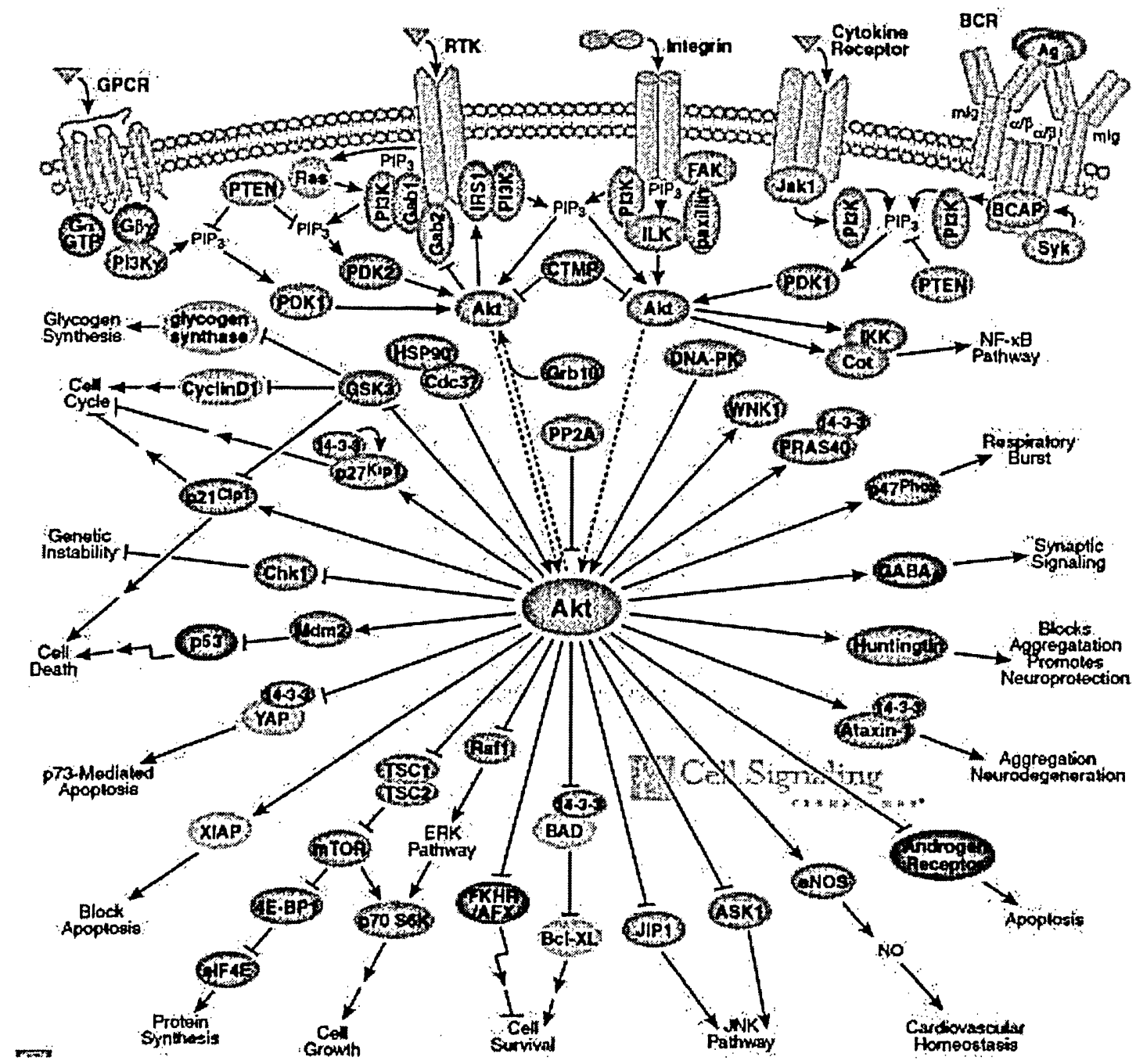

Figure 17 Akt As An Integration Site of Many Signaling Pathways

(http://www.cellsignal.com/reference/pathway/Akt.asp)

Future studies should include experiments where longer infection times are utilized to observe the full activation of signaling pathways. It was thought that some of the proteins such as Caspase-9, did not show full activation as a result of short EPEC infection times.

There is a lot of interest in PI3K signaling because it is relevant in all studies of cell survival. The stimulation of the PI3K/Akt pathway because of its profound effects on cell survival may be an effective approach for preventing and 
treating septic shock (Monick et al., 2001; Pengal et al., 2006). There have been many studies that show how the activation of the Akt pathway plays a crucial role in malignant transformation by inducing cell survival, growth and angiogenesis (Yang et al., 2004). Akt is negatively regulated by the tumor suppressor PTEN and mutations in PTEN have been identified in various tumors (Yang et al., 2004). This study focused on the EPEC infection process and how it can hijack the host cell machinery for its own benefit. However, this research has more far reaching results in that it has created more questions about established theory related to bacterial infection and the signaling pathways that may be affected. The idea of cross-talk between signaling pathways of bacterial invaders and host cells is not new but it does have greater implications with respect to infectious diseases and their possible treatments. 


\subsection{References}

Abul-Milh, M., Wu, Y., Lau, B., Lingwood, C. A., \& Barnett Foster, D. (2001). Induction of epithelial cell death including apoptosis by enteropathogenic Escherichia coli expressing bundle-forming pili. Infection and Immunity, 69(12), 7356-7364.

Akashi-Takamura, S., \& Miyake, K. (2006). Toll-like receptors (TLRs) and immune disorders. Journal of Infection and Chemotherapy : Official Journal of the Japan Society of Chemotherapy, 12(5), 233-240.

Amor, K., Heinrichs, D. E., Frirdich, E., Ziebell, K., Johnson, R. P., \& Whitfield, C. (2000). Distribution of core oligosaccharide types in lipopolysaccharides from escherichia coli. Infection and Immunity, 68(3), 1116-1124.

Bannerman, D. D., \& Goldblum, S. E. (2003). Mechanisms of bacterial lipopolysaccharide-induced endothelial apoptosis. American Journal of Physiology. Lung Cellular and Molecular Physiology, 284(6), L899-914.

Barnett Foster, D., Philpott, D., Abul-Milh, M., Huesca, M., Sherman, P. M., \& Lingwood, C. A. (1999). Phosphatidylethanolamine recognition promotes enteropathogenic $E$. coli and enterohemorrhagic $E$. coli host cell attachment. Microbial Pathogenesis, 27(5), 289-301.

Barwe, S. P., Anilkumar, G., Moon, S. Y., Zheng, Y., Whitelegge, J. P., \& Rajasekaran, S. A., et al. (2005). Novel role for na,K-ATPase in phosphatidylinositol 3-kinase signaling and suppression of cell motility. Molecular Biology of the Cell, 16(3), 1082-1094.

Bonifacino, J. S. (Ed.). (2001). Protocols in cell biology. USA: John Wiley and Sons Inc. 18.1

Boulares, A. H., Yakovlev, A. G., Ivanova, V., Stoica, B. A., Wang, G., \& Iyer, S., et al. (1999). Role of poly(ADP-ribose) polymerase (PARP) cleavage in apoptosis. caspase 3-resistant PARP mutant increases rates of apoptosis in transfected cells. Journal of Biological Chemistry, 274(33), 22932-22940.

Boya, P., Gonzalez-Polo, R. A., Casares, N., Perfettini, J. L., Dessen, P., \& Larochette, N., et al. (2005). Inhibition of macroautophagy triggers apoptosis. Molecular and Cellular Biology, 25(3), 1025-1040.

Bratton, S. B., MacFarlane, M., Cain, K., \& Cohen, G. M. (2000). Protein complexes activate distinct caspase cascades in death receptor and stressinduced apoptosis. Experimental Cell Research, 256(1), 27-33. 
Celli, J., Olivier, M., \& Finlay, B. B. (2001). Enteropathogenic Escherichia coli mediates antiphagocytosis through the inhibition of PI 3-kinase-dependent pathways. The EMBO Journal, 20(6), 1245-1258.

Crane, J. K., Majumdar, S., \& Pickhardt, D. F.,3rd. (1999). Host cell death due to enteropathogenic Escherichia coli has features of apoptosis. Infection and Immunity, 67(5), 2575-2584.

Datta, S. R., Brunet, A., \& Greenberg, M. E. (1999). Cellular survival: A play in three akts. Genes \& Development, 13(22), 2905-2927.

de Grado, M., Rosenberger, C. M., Gauthier, A., Vallance, B. A., \& Finlay, B. B. (2001). Enteropathogenic escherichia coli infection induces expression of the early growth response factor by activating mitogen-activated protein kinase cascades in epithelial cells. Infection and Immunity, 69(10), 6217-6224.

Fort, M. M., Mozaffarian, A., Stover, A. G., Correia Jda, S., Johnson, D. A., \& Crane, R. T., et al. (2005). A synthetic TLR4 antagonist has antiinflammatory effects in two murine models of inflammatory bowel disease. Journal of Immunology (Baltimore, Md. : 1950), 174(10), 6416-6423.

Franzoso, G., Carlson, L., Brown, K., Daucher, P., Bressler, \& Siebenlist, U. (1996). Activation of serum response factor by p65/NF-kB. EMBO Journal, 15(13), 3403-3412.

Fujioka, S., Niu, J., Schmidt, C., Sclabas, G., Peng, B., Uwagawa, T., Li, Z., Evans, B., Abbruzzese, \& J., Chiao, P. (2004). NF-kB and AP-1 connection: Mechanism of NF-KB-dependent regulation of AP-1 activity. Molecular \& Cellular Biology, 24(17), 7806-7819.

Giron, J. A., Ho, A. S., \& Schoolnik, G. K. (1991). An inducible bundle-forming pilus of enteropathogenic escherichia coli. Science, 254(5032), 710-713.

Giron, J. A., Torres, A. G., Freer, E., \& Kaper, J. B. (2002). The flagella of enteropathogenic escherichia coli mediate adherence to epithelial cells. Molecular Microbiology, 44(2), 361-379.

Goldblum, S. E., Brann, T. W., Ding, X., Pugin, J., \& Tobias, P. S. (1994). Lipopolysaccharide (LPS)-binding protein and soluble CD14 function as accessory molecules for LPS-induced changes in endothelial barrier function, in vitro. The Journal of Clinical Investigation, 93(2), 692-702.

Goosney, D. L., Knoechel, D. G., \& Finlay, B. B. (1999). Enteropathogenic E. coli, salmonella, and shigella: Masters of host cell cytoskeletal exploitation. Emerging Infectious Diseases (Print), 5(2), 216-223.

Hilbi, H. (2006). Modulation of phosphoinositide metabolism by pathogenic bacteria. Cellular Microbiology, 8(11), 1697-1706. 
Hirano, M., Kikuchi, Y., Nisitani, S., Yamaguchi, A., Satoh, A., \& Ito, T. (2004). Bruton's tyrosine kinase (btk) enhances transcriptional co-activation activity of BAM11, a btk-associated molecule of a subunit of SWI/SNF complexes. International Immunology, 16(5), 747-757.

Hoare, A., Bittner, M., Carter, J., Alvarez, S., Zaldivar, M., \& Bravo, D. (2006). The outer core lipopolysaccharide of Salmonella enterica serovar typhi is required for bacterial entry into epithelial cells. Infection and Immunity, 74(3), 1555-1564.

Huang, X., Chen, H., Wang, L., \& Lin, Y. (1998). Influence of dextran 40 and dextran 70 on the adhesion of erythrocytes to endothelial cells. Journal of Biomedical Engineering, 15(3), 239-242.

Hui, H., Dotta, F., Di Mario, U., \& Perfetti, R. (2004). Role of caspases in the regulation of apoptotic pancreatic islet beta-cells death. Journal of Cellular Physiology, 200(2), 177-200.

Jacobsen, S., Toelboell, T., \& Andersen, P. H. (2005). Dose dependency and individual variability in selected clinical, haematological and blood biochemical responses after systemic lipopolysaccharide challenge in cattle. Veterinary Research, 36(2), 167-178.

Kaufmann, A., Musset, B., Limberg, S. H., Renigunta, V., Sus, R., \& Dalpke, A. $H$., et al. (2005). "Host tissue damage" signal ATP promotes non-directional migration and negatively regulates toll-like receptor signaling in human monocytes. Journal of Biological Chemistry, 280(37), 32459-32467.

Khursigara, C., Abul-Milh, M., Lau, B., Giron, J. A., Lingwood, C. A., \& Barnett Foster, D. E. (2001). Enteropathogenic Escherichia coli virulence factor bundle-forming pilus has a binding specificity for phosphatidylethanolamine. Infection and Immunity, 69(11), 6573-6579.

Kierbel, A., Gassama-Diagne, A., Mostov, K., \& Engel, J. N. (2005). The phosphoinositol-3-kinase-protein kinase B/Akt pathway is critical for pseudomonas aeruginosa strain PAK internalization. Molecular Biology of the Cell, 16(5), 2577-2585.

Klein, J. B., Buridi, A., Coxon, P. Y., Rane, M. J., Manning, T., \& Kettritz, R., et al. (2001). Role of extracellular signal-regulated kinase and phosphatidylinositol3 kinase in chemoattractant and LPS delay of constitutive neutrophil apoptosis. Cellular Signalling, 13(5), 335-343.

Lien, E., Means, T., Heine, H., Yoshimura, A., Kusumoto, S., Fukase, K., Fenton, M., Oikawa, M., Qureshi, N., Monks, B., Finberg, R., Ingalls, R., Golenbock, D. (2000) Toll-like receptor 4 imparts ligand-specific recognition of bacterial lipopolysaccharide. Journal of Clinical Investigations, 105(4), 497-504. 
Lucchini, S., Liu, H., Jin, Q., Hinton, J. C., \& Yu, J. (2005). Transcriptional adaptation of Shigella flexneri during infection of macrophages and epithelial cells: Insights into the strategies of a cytosolic bacterial pathogen. Infection and Immunity, 73(1), 88-102.

Maier, D., Jones, G., Li, X., Schonthal, A. H., Gratzl, O., \& Van Meir, E. G. (1999). The PTEN lipid phosphatase domain is not required to inhibit invasion of glioma cells. Cancer Research, 59(21), 5479-5482.

Mantis, N., Prevost, M. C., \& Sansonetti, P. (1996). Analysis of epithelial cell stress response during infection by shigella flexneri. Infection and Immunity, 64(7), 2474-2482.

Marshall, A. J., Krahn, A. K., Ma, K., Duronio, V., \& Hou, S. (2002). TAPP1 and TAPP2 are targets of phosphatidylinositol 3-kinase signaling in B cells: Sustained plasma membrane recruitment triggered by the B-cell antigen receptor. Molecular and Cellular Biology, 22(15), 5479-5491.

Michgehl, S., Heusipp, G., Greune, L., Ruter, C., \& Schmidt, M. A. (2006). Espindependent functional integration of the translocated intimin receptor (tir) of enteropathogenic Escherichia coli (EPEC) into host cell membranes. Cellular Microbiology, 8(4), 625-633.

Monick, M. M., Mallampalli, R. K., Carter, A. B., Flaherty, D. M., McCoy, D., \& Robeff, P. K., et al. (2001). Ceramide regulates lipopolysaccharide-induced phosphatidylinositol 3-kinase and akt activity in human alveolar macrophages. Journal of Immunology (Baltimore, Md.: 1950), 167(10), 59775985.

Monick, M. M., Robeff, P. K., Butler, N. S., Flaherty, D. M., Carter, A. B., \& Peterson, M. W. (2002). Phosphatidylinositol 3-kinase activity negatively regulates stability of cyclooxygenase 2 mRNA. The Journal of Biological Chemistry, 277(36), 32992-33000.

Nougayrede, J. P., \& Donnenberg, M. S. (2004). Enteropathogenic Escherichia coli EspF is targeted to mitochondria and is required to initiate the mitochondrial death pathway. Cellular Microbiology, 6(11), 1097-1111.

Nougayrede, J. P., Fernandes, P. J., \& Donnenberg, M. S. (2003). Adhesion of enteropathogenic Escherichia coli to host cells. Cellular Microbiology, 5(6), 359-372.

Patel, T. R., \& Corbett, S. A. (2004). Simvastatin suppresses LPS-induced akt phosphorylation in the human monocyte cell line THP-1. The Journal of Surgical Research, 116(1), 116-120.

Pengal, R. A., Ganesan, L. P., Wei, G., Fang, H., Ostrowski, M. C., \& Tridandapani, S. (2006). Lipopolysaccharide-induced production of 
interleukin-10 is promoted by the serine/threonine kinase akt. Molecular Immunology, 43(10), 1557-1564.

Pizarro-Cerda, J., \& Cossart, P. (2004). Subversion of phosphoinositide metabolism by intracellular bacterial pathogens. Nature Cell Biology, 6(11), 1026-1033.

Quitard, S., Dean, P., Maresca, M., \& Kenny, B. (2006). The enteropathogenic escherichia coli EspF effector molecule inhibits PI-3 kinase-mediated uptake independently of mitochondrial targeting. Cellular Microbiology, 8(6), 972981.

Raina, D., Pandey, P., Ahmad, R., Bharti, A., Ren, J., \& Kharbanda, S. (2005). cabl tyrosine kinase regulates caspase- 9 autocleavage in the apoptotic response to DNA damage. The Journal of Biological Chemistry, 280(12), 11147-11151.

Salh, B., Wagey, R., Marotta, A., Tao, J. S., \& Pelech, S. (1998). Activation of phosphatidylinositol 3-kinase, protein kinase $B$, and p70 S6 kinases in lipopolysaccharide-stimulated raw 264.7 cells: Differential effects of rapamycin, Ly294002, and wortmannin on nitric oxide production. Journal of Immunology (Baltimore, Md.: 1950), 161(12), 6947-6954.

Sansonetti, P. J. (2004). War and peace at mucosal surfaces. Nature Reviews.Immunology, 4(12), 953-964.

Savkovic, S. D., Koutsouris, A., \& Hecht, G. (1996). Attachment of a noninvasive enteric pathogen, enteropathogenic escherichia coli, to cultured human intestinal epithelial monolayers induces transmigration of neutrophils. Infection and Immunity, 64(11), 4480-4487.

Schratt, G., Philippar, U., Hockemeyer, D., Schwartz, H., Alberti, S., \& Nordheim, A. (2004). SRF regulates Bcl-2 expression and promotes cell survival during murine embryonic development. EMBO Journal, 23(8), 1834-1844.

Sinclair, J. F., Dean-Nystrom, E. A., \& O'Brien, A. D. (2006). The established intimin receptor tir and the putative eucaryotic intimin receptors nucleolin and beta1 integrin localize at or near the site of enterohemorrhagic escherichia coli 0157:H7 adherence to enterocytes in vivo. Infection and Immunity, 74(2), 1255-1265.

Suzuki, M., Hisamatsu, T., \& Podolsky, D. K. (2003). Gamma interferon augments the intracellular pathway for lipopolysaccharide (LPS) recognition in human intestinal epithelial cells through coordinated up-regulation of LPS uptake and expression of the intracellular toll-like receptor 4-MD-2 complex. Infection and Immunity, 71(6), 3503-3511. 
Takeda, K., Akagi, S., Takahashi, S., Onishi, A., Hanada, H., \& Pinkert, C. A. (2002). Mitochondrial activity in response to serum starvation in bovine (bos taurus) cell culture. Cloning and Stem Cells, 4(3), 223-229.

Tang, D., Okada, H., Ruland, J., Liu, L., Stambolic, V., \& Mak, T. W. (2001). Akt is activated in response to an apoptotic signal. Journal of Biological Chemistry, 276(32), 30461-30466.

Tikhomirov, O., \& Carpenter, G. (2005). Bax activation and translocation to mitochondria mediate EGF-induced programmed cell death. Journal of Cell Science, 118(Pt 24), 5681-5690.

Torres, A. G., Zhou, X., \& Kaper, J. B. (2005). Adherence of diarrheagenic Escherichia coli strains to epithelial cells. Infection and Immunity, 73(1), 1829.

Vallance, B. A., \& Finlay, B. B. (2000). Exploitation of host cells by enteropathogenic Escherichia coli. Proceedings of the National Academy of Sciences of the United States of America, 97(16), 8799-8806.

Vander Heiden, M. G., Chandel, N. S., Williamson, E. K., Schumacker, P. T., \& Thompson, C. B. (1997). Bcl-xL regulates the membrane potential and volume homeostasis of mitochondria. Cell, 91(5), 627-637.

Varnai, P., \& Balla, T. (1998). Visualization of phosphoinositides that bind pleckstrin homology domains: Calcium- and agonist-induced dynamic changes and relationship to myo-[3H]inositol-labeled phosphoinositide pools. The Journal of Cell Biology, 143(2), 501-510.

Varnai, P., Bondeva, T., Tamas, P., Toth, B., Buday, L., \& Hunyady, L. (2005). Selective cellular effects of overexpressed pleckstrin-homology domains that recognize Ptdlns $(3,4,5) \mathrm{P} 3$ suggest their interaction with protein binding partners. Journal of Cell Science, 118(Pt 20), 4879-4888.

Varnai, P., Rother, K. I., \& Balla, T. (1999). Phosphatidylinositol 3-kinasedependent membrane association of the bruton's tyrosine kinase pleckstrin homology domain visualized in single living cells. The Journal of Biological Chemistry, 274(16), 10983-10989.

Vivarelli, M. S., McDonald, D., Miller, M., Cusson, N., Kelliher, M., \& Geha, R. S. (2004). RIP links TLR4 to akt and is essential for cell survival in response to LPS stimulation. The Journal of Experimental Medicine, 200(3), 399-404.

Whitfield, C. (2006). Biosynthesis and assembly of capsular polysaccharides in Escherichia coli. Annual Review of Biochemistry, 75, 39-68. 
Whitfield, C., \& Roberts, I. S. (1999). Structure, assembly and regulation of expression of capsules in Escherichia coli. Molecular Microbiology, 31(5), 1307-1319.

Wu, Y., Lau, B., Smith, S., Troyan, K., \& Barnett Foster, D. (2004). Enteropathogenic Eschericia coli infection triggers host phospholipid metabolism perturbations. Infection and Immunity, 72, 6764.

Yang, L., Dan, H. C., Sun, M., Liu, Q., Sun, X. M., \& Feldman, R. I., et al. (2004). Akt/protein kinase $B$ signaling inhibitor-2, a selective small molecule inhibitor of akt signaling with antitumor activity in cancer cells overexpressing akt. Cancer Research, 64(13), 4394-4399.

Zheng, J., Watson, A. D., \& Kerr, D. E. (2006). Genome-wide expression analysis of lipopolysaccharide-induced mastitis in a mouse model. Infection and Immunity, 74(3), 1907-1915.

Zughaier, S. M., Tzeng, Y. L., Zimmer, S. M., Datta, A., Carlson, R. W., \& Stephens, D. S. (2004). Neisseria meningitidis lipooligosaccharide structuredependent activation of the macrophage CD14/Toll-like receptor 4 pathway. Infection and Immunity, 72(1), 371-380.

B'-1:-1:3

65 